LAWRENCE LIVERMORE N A T IO N A L LABORATORY
Review of Wind Energy Forecasting Methods for Modeling Ramping Events

S. Wharton, J. K. Lundquist, N. Marjanovic, J. L. Williams, M. Rhodes, T. K. Chow, R. Maxwell

March 29, 2011 
This document was prepared as an account of work sponsored by an agency of the United States government. Neither the United States government nor Lawrence Livermore National Security, LLC, nor any of their employees makes any warranty, expressed or implied, or assumes any legal liability or responsibility for the accuracy, completeness, or usefulness of any information, apparatus, product, or process disclosed, or represents that its use would not infringe privately owned rights. Reference herein to any specific commercial product, process, or service by trade name, trademark, manufacturer, or otherwise does not necessarily constitute or imply its endorsement, recommendation, or favoring by the United States government or Lawrence Livermore National Security, LLC. The views and opinions of authors expressed herein do not necessarily state or reflect those of the United States government or Lawrence Livermore National Security, LLC, and shall not be used for advertising or product endorsement purposes.

This work performed under the auspices of the U.S. Department of Energy by Lawrence Livermore National Laboratory under Contract DE-AC52-07NA27344. 


\section{Review of Wind Energy Forecasting Methods for Modeling Ramping Events}

Sonia Wharton, Lawrence Livermore National Laboratory

With contributions from Tina K. Chow (University of California, Berkeley), Julie K. Lundquist (University of Colorado, Boulder), Nikola Marjanovic (University of California, Berkeley), Reed Maxwell (Colorado School of Mines), Michael Rhodes (University of Colorado, Boulder), and John L. Williams (Colorado School of Mines)

Technical Report LLNL-TR-476934 to the DOE Wind and Water Power Program March 31, 2011 


\section{Executive Summary}

\section{Relevance to the DOE Wind Power Program and wind industry}

Tall onshore wind turbines, with hub heights between $80 \mathrm{~m}$ and $100 \mathrm{~m}$, can extract large amounts of energy from the atmosphere since they generally encounter higher wind speeds, but they face challenges given the complexity of boundary layer flows. This complexity of the lowest layers of the atmosphere, where wind turbines reside, has made conventional modeling efforts less than ideal. To meet the nation's goal of increasing wind power into the U.S. electrical grid, the accuracy of wind power forecasts must be improved.

In this report, the Lawrence Livermore National Laboratory, in collaboration with the University of Colorado at Boulder, University of California at Berkeley, and Colorado School of Mines, evaluates innovative approaches to forecasting sudden changes in wind speed or "ramping events" at an onshore, multimegawatt wind farm. The forecast simulations are compared to observations of wind speed and direction from tall meteorological towers and a remote-sensing Sound Detection and Ranging (SODAR) instrument.

Ramping events, i.e., sudden increases or decreases in wind speed and hence, power generated by a turbine, are especially problematic for wind farm operators. Sudden changes in wind speed or direction can lead to large power generation differences across a wind farm and are very difficult to predict with current forecasting tools. Here, we quantify the ability of three models, mesoscale WRF, WRF-LES, and PF.WRF, which vary in sophistication and required user expertise, to predict three ramping events at a North American wind farm. 


\section{A brief look at the forecast models}

- WRF mesoscale: In Chapter 2, the numerical Weather and Research Forecasting model (WRF) is applied to the wind park domain in mesoscale forecasting mode, with no perturbations made to the model physics. Here, WRF is considered the control run and is used to simulate an "out-of-thebox" version of WRF which requires minimal expertise from the user and minimal input about site conditions. Mesoscale WRF with "skilled" user input changes to horizontal and vertical resolution, nesting levels, and land surface conditions is applied in Chapter 3.

- WRF-LES: A novel application of large-eddy simulation (LES) to wind energy forecasting is examined in Chapter 3. WRF-LES is a high-resolution, turbulence-resolving mode of WRF. Here, WRF-LES is tested with two LES closure schemes: a turbulent kinetic energy closure of order 1.5 (TKE 1.5) and the Dynamic Reconstruction Model (DRM).

- PF.WRF: The influence of subsurface hydrology and hence, surface exchanges of heat and moisture on wind conditions is examined in Chapter 4. PF.WRF is a fully-coupled, groundwater-to-atmosphere model which incorporates the 3-D, variably-saturated hydrologic model ParFlow and WRF to simulate physics from bedrock to the top of the atmosphere.

\section{A brief look at the forecasted ramping events}

The ramping events include times of rapid increases in wind speed during a synoptically-forced period in February (Case S), a locally-forced period in May, and a locally-forced period in July (Case L). Case S occurred during the wet season 
and was caused by a frontal passage while the locally-driven events occurred during the warm, dry season and were induced by a strong sea breeze.

\section{Model intercomparison results}

Model performance was assessed by examining root mean square errors between the forecasted wind speeds and observations. The most significant model differences are shown here for the synoptic ramping event:

\begin{tabular}{|c|c|}
\hline MODEL CONFIGURATIONS & RMSE (m/s) \\
\hline \multicolumn{2}{|c|}{ unskilled "out-of-the-box" mesoscale WRF } \\
\hline \multicolumn{2}{|l|}{ Different horizontal resolutions } \\
\hline $900 \mathrm{~m}$ & 4.74 \\
\hline $2700 \mathrm{~m}$ & 4.92 \\
\hline $8100 \mathrm{~m}$ & 2.99 \\
\hline \multicolumn{2}{|l|}{ skilled mesoscale WRF } \\
\hline \multicolumn{2}{|l|}{ Different horizontal resolutions } \\
\hline $300 \mathrm{~m}$ & 2.30 \\
\hline $900 \mathrm{~m}$ & 2.23 \\
\hline $2700 \mathrm{~m}$ & 2.16 \\
\hline $8100 \mathrm{~m}$ & 2.30 \\
\hline \multicolumn{2}{|l|}{ Different vertical spacing } \\
\hline 40 (standard WRF) & 2.39 \\
\hline 49 (tanh spaced) & 2.30 \\
\hline $70(10 \mathrm{~m}$ spacing in the lowest $200 \mathrm{~m})$ & 2.33 \\
\hline \multicolumn{2}{|l|}{ WRF-LES with 1.5 TKE closure } \\
\hline \multicolumn{2}{|l|}{ Different horizontal resolutions } \\
\hline $100 \mathrm{~m}$ & 2.43 \\
\hline $300 \mathrm{~m}$ & 3.14 \\
\hline $900 \mathrm{~m}$ & 5.51 \\
\hline
\end{tabular}

Average root mean square errors $(\mathrm{m} / \mathrm{s})$ for the model simulations of the February ramping event. RMSE is the error between the forecast simulations of 0-200 m AGL wind speed and observations of 0-200 m AGL wind speed. 
Although the minimum RMSE from the "out-of-the-box" mesoscale WRF runs was relatively low, the range of RMSE values was high and showed uneven performance of the base model. This indicates that the set-up and execution of simulations for wind power forecasting requires skill and tuning of the simulations for a specific wind farm site. Overall, the "out-of-the-box" WRF mesoscale simulations failed to capture the timing and shape of the wind profile at heights found in the rotor disk. On the other hand, "skilled" runs of mesoscale WRF which included experimentation with horizontal and vertical resolution and 2-way nesting showed significant improvement over the base model and reduced the RMSE by $\sim 2 \mathrm{~m} / \mathrm{s}$. Interestingly, running the finer horizontal resolutions did not improve the forecast simulations as expected. This suggests that all of the model grids, even as course as $2.7 \mathrm{~km}$, are adequate to use at a wind farm in relatively simple topography, including the one studied here which has elevation gains of less than $120 \mathrm{~m}$. At very fine resolutions, the LES turbulence closures performed well, but there was little added benefit to accuracy. The third model, PF.WRF, appeared to capture the magnitude of the wind speeds associated with the ramping events reasonably well, and showed consistent results, but had difficulty in forecasting the timing of ramping events which led to significantly higher RMSE.

\section{Future recommendations for wind ramp forecasting}

While our findings are based on a few case studies and longer simulation runs would reveal additional insight into the model specifications needed for accurate ramp forecasting, our results suggest that the "out-of-the-box" mesoscale version of WRF is likely inadequate for ramp forecasting at most multi-megawatt wind farms; this deficiency will only increase for forecasts for 
wind farms in complex terrain. Future work is needed to investigate the effects of higher resolution on forecasts for wind farms in complex terrain as the wind farm in this study is located in relatively simple topography. We suggest that future forecasting of ramping events should exploit recent developments in refined simulations, including large-eddy simulation. The location and seasonal timing of ramp events studied here might not have fully showed the utility of a coupled subsurface-surface-atmosphere model. Either soil conditions were too dry during the ramping events (except for the February case) to show PF.WRF's full utility in parameterizing surface energy and moisture exchange, or the groundwater influence on surface moisture was not significant at this site as it is at other locations. Further utility of PF.WRF should be tested by expanding the model domain to capture non-localized effects of soil moisture heterogeneity. 


\section{Chapter 1: Introduction}

Although wind energy capacity is rapidly increasing in the United States and around the world, managing the integration of this fluctuating power sources into power grids designed for scheduled production requires new technological approaches. Because electric utility companies usually have a specific generation configuration, which may consist of a mix of coal, natural gas, hydropower, and wind power, any change in the power generated by the wind requires an accompanying change in another power source. "Ramps", or rapid increases or decreases in power availability from the wind, are caused by rapid changes in the wind due to a range of meteorological phenomena including frontal passages, thunderstorm outflow, topographicallyinduced flows such as sea breezes and density currents, among others. Ramping events can occur regularly; an investigation by Kamath et al. (2010) find that, in the Bonneville Power Administration territory, as wind generation increases, larger ramps become more common. To ensure that adequate power will be available to fulfill demand even in the case of wind speed decreases that "ramp down" available power, operating utilities frequently maintain a spinning reserve of gas turbine generators running ready to fill any gap. Spinning reserves are typically quite expensive and increase carbon dioxide emissions. Therefore, utility companies and wind farm owner/operators have a need to forecast, with accuracy, the likelihood of a ramping event to ensure that minimal spinning reserves are maintained.

Wind power forecasting is plagued with difficulties in accurately predicting the occurrence and intensity of atmospheric conditions at the heights spanned by industrial-scale turbines ( 40 to $200 \mathrm{~m}$ above ground level). Better simulation of the relevant physics would enable operational practices such as integration of large fractions of wind power into power grids, scheduling maintenance on wind energy facilities, and deciding design criteria for next- 
generation turbines and siting. Increases in available computational power have made highresolution simulations of the atmospheric boundary layer more practical. The model operator, however, is required to make proper choices regarding model grid spacing, turbulence parameterization, land surface representations and the configuration of initial and lateral boundary conditions for accurate simulations. The proper choice of these parameters is highly dependent on the situation under consideration. As Porter and Rogers (2010) discuss, numerical weather prediction models like the Weather Research and Forecasting (WRF) model are in widespread use for wind power prediction. WRF is discussed in detail in Skamarock and Klemp (2008).

\subsection{Wind farm site and measurement details}

The wind farm studied here is located in western North America at an elevation of near sea level, with some marine boundary layer influences. It covers an area of about $6 \mathrm{~km}$ by $10 \mathrm{~km}$ with a fairly flat topography that includes rolling, grass-covered hills with elevation changes less than $120 \mathrm{~m}$ (Figure 1). Portions of the site are used for grazing. The area experiences strong land-sea temperature differences, particularly during the summer months when the land is much warmer than the coastal Pacific waters. The resulting pressure gradient produces strong onshore winds consistently from a westerly or southwesterly direction. The site has two distinct seasons: a wet, cool winter with frequent synoptic storms and a dry, warm summer with little convective storm activity due to the presence of a semi-permanent high pressure circulation over the Pacific Ocean. 


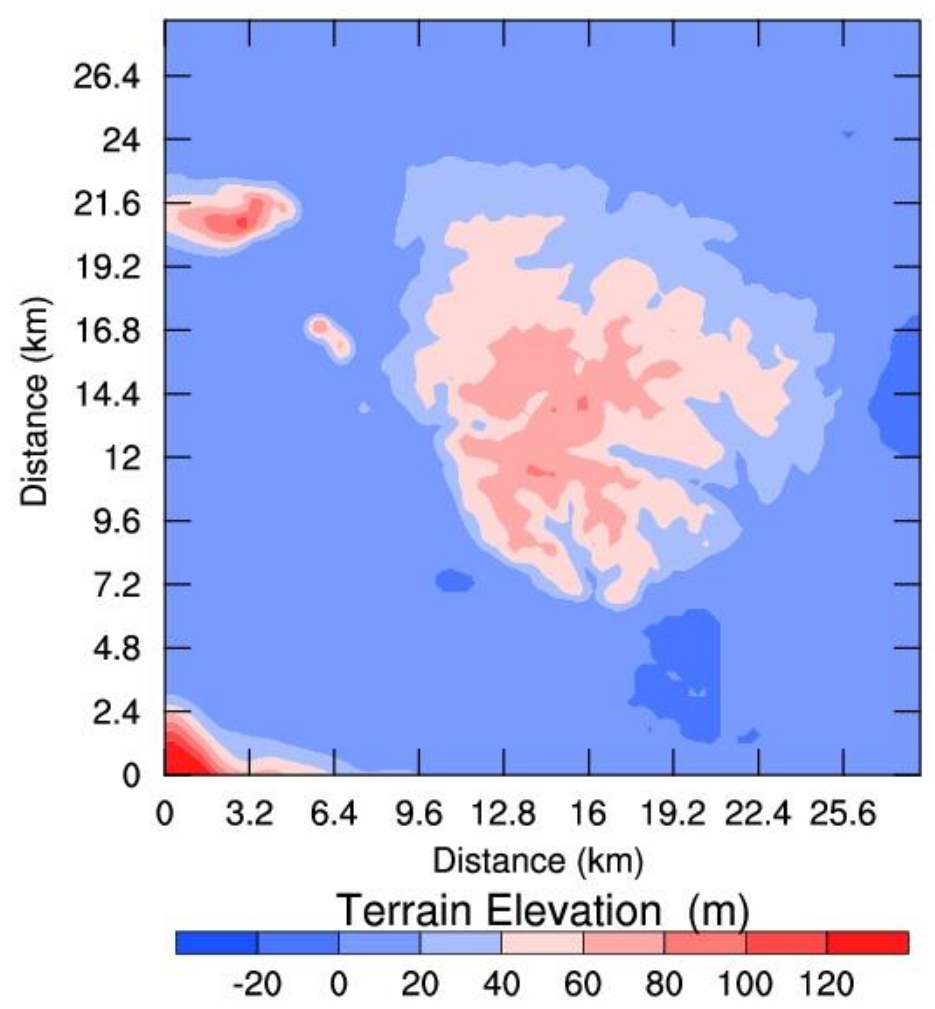

Figure 1. Contour map of the wind farm topography used in the model domains. The elevations range from sea level to $120 \mathrm{~m}$.

Tens of horizontal-axis, three-bladed wind turbines, with rotor diameters of approximately $80 \mathrm{~m}$, are in operation at the wind farm. The blades interact with the instantaneous wind speed in a disk-shaped area across heights of $40 \mathrm{~m}$ to $120 \mathrm{~m}$ above the ground level (AGL), where $40 \mathrm{~m}$ is the minimum blade tip height and $120 \mathrm{~m}$ is the maximum blade tip height. The nacelle and power generators are located at $80 \mathrm{~m}$ AGL (referred to as hubheight). Observations of wind speed and direction are available from a high-resolution remotesensing Sound Detection and Ranging (SODAR) instrument and cup anemometers mounted to two tall meteorological towers. The meteorological towers are located in the upwind, western portion of the wind farm and are equipped with cup anemometers (\#40, NRG Systems, Inc., Hinesburg, Vermont, USA) at heights ranging from $30-50 \mathrm{~m}$ on the $50 \mathrm{~m}$ tall tower and $50-80 \mathrm{~m}$ AGL on the $80 \mathrm{~m}$ tall tower. A Doppler mini SODAR (Model4000, Atmospheric Systems Corporation, Santa Clarita, CA, USA) collected high vertical resolution, three-axis wind velocity 
data in the northern region of the wind farm. The SODAR data includes measurements of threedimensional wind speed $(u, v, w)\left(\mathrm{m} \mathrm{s}^{-1}\right)$ and standard deviations $(\sigma u, \sigma v, \sigma w)\left(\mathrm{m} \mathrm{s}^{-1}\right)$ of each wind component. The measurements were taken from $20 \mathrm{~m}$ to $200 \mathrm{~m}$ AGL in $10 \mathrm{~m}$ intervals and averaged over 10-minute periods.

The water table is estimated to be near the surface in the southern portion of the wind farm and relative to the land surface elsewhere in the model domain. The bedrock geology is dominated by alluvial sands and gravels (Wagner et al. 1981). The dominant soil type over most of the site is clay; however, the southwest portion is predominantly a silt loam with high organic content. Precipitation data was available from a nearby tipping bucket rain gauge.

\subsection{Ramping events}

This report investigates the steps necessary to achieve accurate simulations of the wind fields and "ramping" events at the wind farm. "Ramping" refers here to a rapid increase in wind speed over a short time period and is of great interest to wind farm operators for preventing turbine fatigue and accurate predictions of power output. The exact definition of a ramping event varies in practice; examples include a $20 \%$ capacity change in production over a thirtyminute period (Freedman et al. 2008), or a pre-specified change in the magnitude of system-wide production. Atmospheric conditions have a large effect on the predictability of a ramping event. Meteorologically-driven ramping events may be due to atmospheric motions at several scales. For example, thermally-driven winds such as sea breezes, mountain-valley circulations, or lowlevel jets occur at local scales, whereas the passage of a cold front is a synoptically-driven phenomenon. In all cases, associated wind transitions appear as large ramps in the wind speed 
time series to wind farm systems operators, though the cause for the wind changes can be quite different (Freedman et al. 2008). Larger, synoptically-driven features have longer time scales and should in theory be more straightforward to forecast than local-scale phenomena, which usually require fine scale information about land-surface conditions and turbulent mixing in the atmosphere. Low resolution mesoscale models may be adequate for many situations if the major features of the terrain are adequately captured by the models (i.e., the terrain is non-complex).

\subsection{Meteorological conditions on case study days}

\section{Synoptic event in February (Case S)}

The synoptically-driven ramping event (Case S) in February was caused by a frontal passage and peak wind speeds were observed at approximately 18:00 UTC (10:00 PST) at which point the wind speed magnitude increased from 3 to $15 \mathrm{~m} / \mathrm{s}$ over a 50 minute period. Surface reanalysis maps indicate that the high pressure system was located to the northwest of the wind farm. A ridge extended from the high pressure center to the southeast. Over the course of the two days under consideration, the high pressure system moved out to the east. This ramping event occurred during the wet season and followed a significant rain event two weeks earlier. Soil saturation conditions were relatively high.

\section{Local event in May}

The locally-driven ramping event in May was caused by strong differential heating between the interior land surface and cooler Pacific waters. The subsequent pressure difference created a strong, onshore sea-breeze from the west. The peak observed wind for the May ramping event occurred at approximately 18:00 UTC (10:00 PST). The observed wind ramp 
reached a speed of approximately $15 \mathrm{~m} / \mathrm{s}$, an increase of $8 \mathrm{~m} / \mathrm{s}$ in less than an hour. A rain gauge near the site recorded no substantial rainfall within the forty-five days preceding the event and soil saturation conditions were relatively low-to-moderate.

\section{Local event in July (Case L)}

The locally-driven ramping event (Case L) was also caused by a strong sea breeze from the west. The peak wind speed occurred at 8:00 UTC (24:00 PST) at which point the wind speed magnitude had increased from 2 to $14 \mathrm{~m} / \mathrm{s}$ in just over 8 hours. The Case L ramping event occurred in mid-dry season and the most recent rainfall was more than seventy days earlier. Soil saturation conditions at the wind farm were very low.

\subsection{Outline of the report}

The remainder of this report is organized into Chapters 2-4, which discuss each forecast model's ability to simulate the ramping events as compared to meteorological observations. Chapter 2 describes the set-up and results from using "out-of-the-box" mesocale WRF for the February, synoptically-driven event. The two locally-driven ramping events, as well as the synoptic-event, are simulated using mesoscale WRF with "skilled" user input and WRF-LES in Chapter 3, and PF.WRF in Chapter 4. Chapter 5 compares the forecasting runs and provides guidance for future renewable forecasting efforts. 


\section{Chapter 2: Mesoscale WRF}

There is no clear-cut description of an optimal configuration of the Weather and Research Forecasting (WRF) model for wind energy prediction. Investigations including Storm et al. (2009), for example, find inadequacies in all available parameterizations, particularly for investigations of those atmospheric phenomena critical for wind energy. In this chapter, WRF is used in mesoscale mode to simulate the February, synoptically-driven ramping event (Case S). This is an "out-of-the-box" version of WRF which requires minimal user expertise or sitespecific parameters. WRF was run at three horizontal resolutions: $8100 \mathrm{~m}, 2700 \mathrm{~m}$, and $900 \mathrm{~m}$, with one of two Planetary Boundary Layer (PBL) schemes: Yonsei University (YSU) or the Mellor-Yamada-Janjic (MYJ). The three horizontal resolutions were run simultaneously using one-way nesting such that the boundary conditions for each higher-resolution grid ("nested grid") are taken from the solution on the lower-resolution grid ("coarse grid"). The same PBL scheme was used in all grids within a given simulation. Finally, model forecasts of wind speed and direction are compared to SODAR observations for the 48-hour time period encompassing the ramping event.

\subsection{WRF Simulations}

The WRF simulations here are intended to represent, as much as possible, simulations by a beginner WRF user without significant tuning for the wind farm under investigation. WRF version 3.2 (released March 2010) was used for the simulations. Default choices of the vertical profile and physics options were used. The WRF simulations were initialized with data from the North American Regional Reanalysis (NARR), provided by the National Center for Atmospheric Research (NCAR). This reanalysis product integrates observations, including precipitation, 
radar profiler data, and numerous land surface and moisture datasets with forecasts for an "optimal" set of boundary conditions. The NARR products are on Eta 221 grid $(32 \mathrm{~km}$ horizontal resolution) at 29 pressure levels. The output analyses are 3-hourly with additional 9 variables in the 3-hour forecasts to reflect accumulations or averages. Topography within the WRF domains is represented at approximately $1 \mathrm{~km}$ resolution using the "30 second" topographic and land use/land cover characteristics databases included with WRF distributions. The two sets of simulations presented here differ only in the choice of PBL scheme (bl_pbl_physics) and surface layer scheme (sf_sfclay_physics). Each PBL scheme is run at three different horizontal resolutions. The simulations used identical choices for the other physics options of land surface model (RUC), cumulus parameterizations (none), and longwave and shortwave radiation. It is hypothesized that the choice of PBL schemes will have the most impact on the predictions of boundary-layer winds.

\subsection{Results}

To quantify the performance of each PBL scheme, the root mean square error (RMSE) was calculated for wind speed and wind direction. RMSE was calculated between the model output and the SODAR observations over the 48 hour period containing the wind ramping event. RMSE was calculated for both PBL schemes at the three resolutions and at each height for that resolution. RMSE is defined as,

$$
R M S E=\sqrt{\frac{1}{M} \sum_{j=1}^{M} \frac{1}{N} \sum_{i=1}^{N}\left(A_{i, j}-B_{i, j}\right)^{2}}
$$

where, $\mathrm{M}=$ number of time steps, $\mathrm{N}=$ number of vertical grid points, $\mathrm{A}=$ observation, and $\mathrm{B}=$ simulation data. Table 2.1 lists the RMSE for wind direction. Table 2.2 lists the RMSE for 
horizontal wind speed. At each resolution, the smallest RMSE value is emphasized in bold.

Smaller RMSE values indicate that the model is in closer agreement with the observations.

\begin{tabular}{|c|c|c|}
\cline { 2 - 3 } \multicolumn{1}{c|}{} & $\begin{array}{c}\text { RMSE } \\
\text { (degrees) }\end{array}$ & $\begin{array}{c}\text { RMSE } \\
\text { (degrees) }\end{array}$ \\
\hline $\begin{array}{c}\text { Resolution } \\
\text { (d) }\end{array}$ & YSU $@$ & MYJ \\
\hline $\begin{array}{c}900 \mathrm{~m} \text { m } \\
180 \mathrm{~m}\end{array}$ & 41.0 & 32.9 \\
\hline $\begin{array}{c}2700 \mathrm{~m} @(6.5 \\
100 \mathrm{~m}\end{array}$ & 45.8 & $\mathbf{1 4 . 3}$ \\
\hline $\begin{array}{c}2700 \mathrm{~m} @ \\
170 \mathrm{~m}\end{array}$ & 30.6 & $\mathbf{2 1 . 7}$ \\
\hline $\begin{array}{c}8100 \mathrm{~m} @ \\
60 \mathrm{~m}\end{array}$ & 53.4 & 45.1 \\
\hline $\begin{array}{c}8100 \mathrm{~m} @ \\
130 \mathrm{~m}\end{array}$ & 42.1 & $\mathbf{3 5 . 8}$ \\
\hline
\end{tabular}

\begin{tabular}{|c|c|c|}
\cline { 2 - 3 } \multicolumn{1}{c|}{} & $\begin{array}{c}\text { RMSE } \\
\text { (m/s) }\end{array}$ & $\begin{array}{c}\text { RMSE } \\
(\mathrm{m} / \mathrm{s})\end{array}$ \\
\hline \begin{tabular}{c} 
Resolution \\
\hline $\begin{array}{c}900 \mathrm{~m} @ \\
110 \mathrm{~m}\end{array}$
\end{tabular} & YSU & MYJ \\
\hline $\begin{array}{c}900 \mathrm{~m} @ \\
180 \mathrm{~m}\end{array}$ & 5.29 & 4.64 \\
\hline $\begin{array}{c}2700 \mathrm{~m} @ \\
100 \mathrm{~m}\end{array}$ & 3.56 & 5.77 \\
\hline $\begin{array}{c}2700 \mathrm{~m} @ \\
170 \mathrm{~m}\end{array}$ & 6.28 & 5.93 \\
\hline $\begin{array}{c}8100 \mathrm{~m} @ \\
60 \mathrm{~m}\end{array}$ & $\mathbf{2 . 3 1}$ & 2.67 \\
\hline $\begin{array}{c}8100 \mathrm{~m} @ \\
130 \mathrm{~m}\end{array}$ & 3.54 & 3.42 \\
\hline
\end{tabular}

Table 2.1 (left) RMSE for forecasted wind direction versus observed at different heights, horizontal resolutions, and PBL schemes. The best agreement between the simulated wind direction and wind speed occurred for the MYJ PBL scheme, at $900 \mathrm{~m}$ horizontal resolution and at $180 \mathrm{~m}$ height. Lower agreement was found at heights in the rotor-disk (40-120 m).

Table 2.2 (right) RMSE for forecasted wind speed versus observed at different heights, horizontal resolutions, and PBL schemes. The best agreement occurred for the YSU PBL scheme, at $8100 \mathrm{~m}$ horizontal resolution and at $60 \mathrm{~m}$ height. Agreement for heights in the rotor-disk are slightly lower (average RMSE $=3.42 \mathrm{~m} / \mathrm{s}$ ).

\section{Wind direction}

The RMSE of wind direction varied between 14 degrees and 53 degrees. This range represents a significant error considering that this site typically experiences channeled, unidirectional flow during most of the year (Wharton and Lundquist, 2010). The large RMSE of wind direction therefore suggests that the timing of the rotation of the wind vector that 
accompanies the ramping event was incorrect for both cases, as will be discussed below and shown in Figures 2.1 and 2.2. Figure 2.1 shows SODAR observations of wind direction at $60 \mathrm{~m}$ height compared to the PBL schemes in WRF run at $8100 \mathrm{~m}$ horizontal resolution. Figure 2.2 shows the comparison for $180 \mathrm{~m}$ height at $900 \mathrm{~m}$ resolution. Higher horizontal resolution (900 $\mathrm{m}$ versus $8100 \mathrm{~m}$ ) appears to have improved the timing of the wind direction shift. In addition, MJY consistently performed better than YSU at all heights examined here; for e.g., YSU predicted the ramp eight hours early while MYJ predicted a more gradual shift in wind direction. Model errors tended to decrease as height increased. However, as shown in Figure 2.2, higher altitudes reported fewer SODAR data; this paucity at high altitudes likely explains the lower RMSE values.

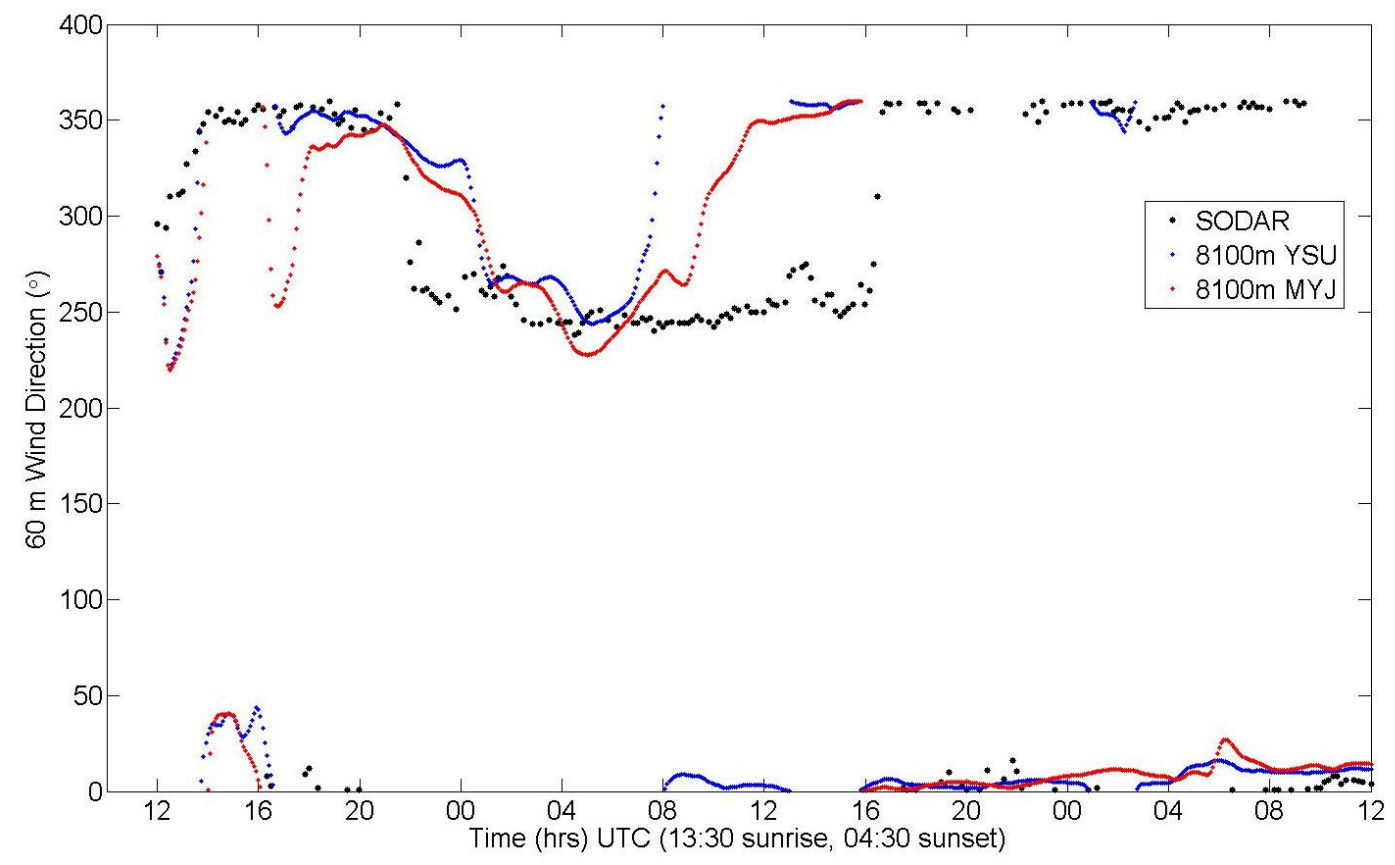

Figure 2.1: Wind direction at $60 \mathrm{~m}$ height for the 8100 meter horizontal resolution runs for Case S. The YSU scheme predicts the magnitude of the wind direction shift accurately but is eight hours early as compared to the SODAR observations. 


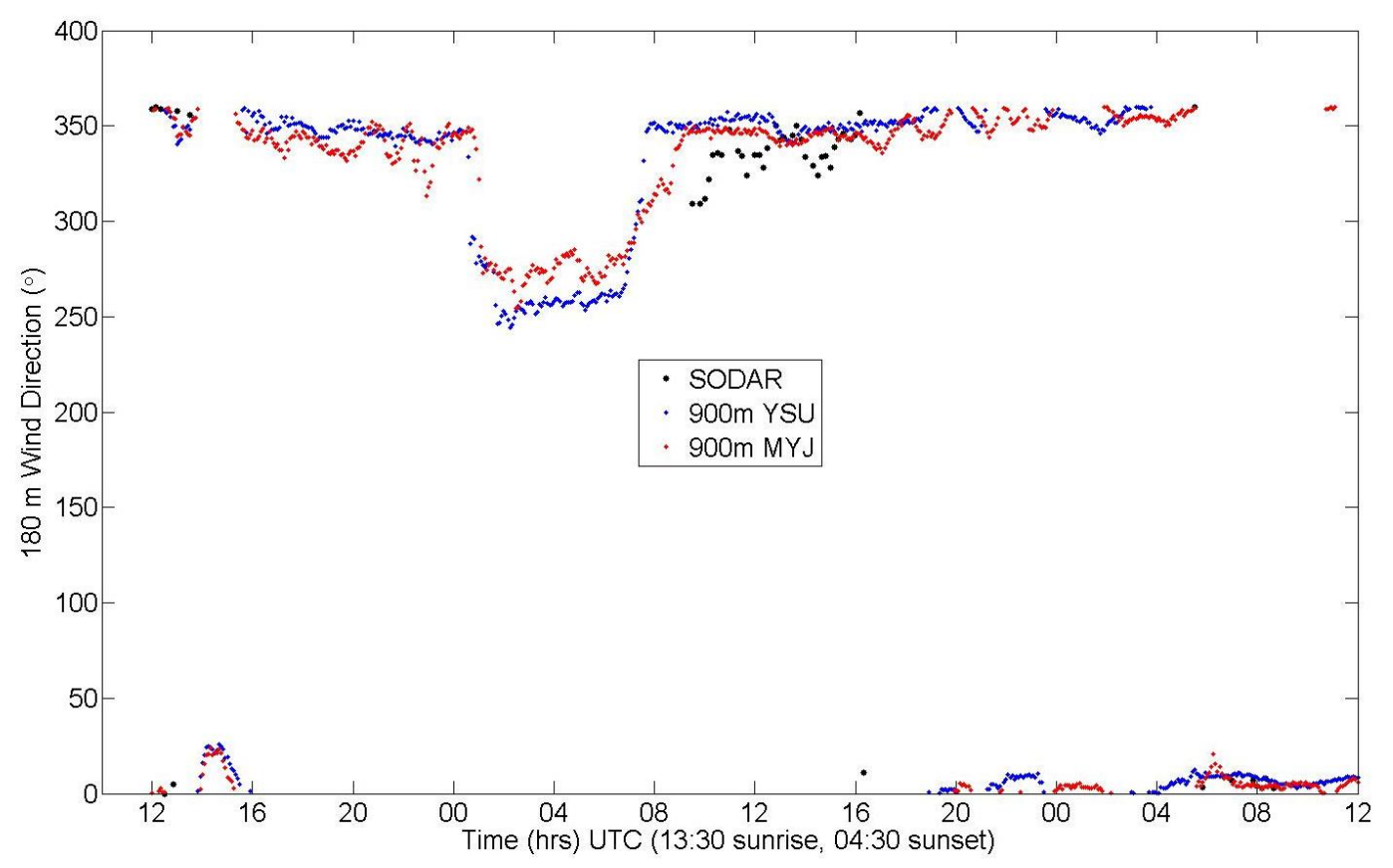

Figure 2.2: Wind direction at $180 \mathrm{~m}$ height for the 900 meter horizontal resolution runs for Case S. Higher resolution improves the forecast accuracy of the wind direction shift. As with the lower resolution $(8100 \mathrm{~m})$, the MYJ scheme shows better agreement with the SODAR observations.

Figure 2.3 shows the wind direction simulations and observations for the $110 \mathrm{~m}$ height at 900 m horizontal resolution. This altitude had more SODAR data available and lower RMSE values. Furthermore, the simulations run with increased horizontal resolution also tended to have smaller RMSE values. The figure shows that the degree of wind direction change associated with the ramp was captured by the model simulations, although the timing did not correspond well to the timing observed by SODAR. While the model did capture the ramping event, the incorrect timing caused relatively high RMSE values in all runs. This mistiming also existed for both $2700 \mathrm{~m}$ model runs (not shown). The mistiming was more noticeable in the lower altitude plot as well (Figure 2.1), which could also potentially cause the higher RMSE values for lower heights. 


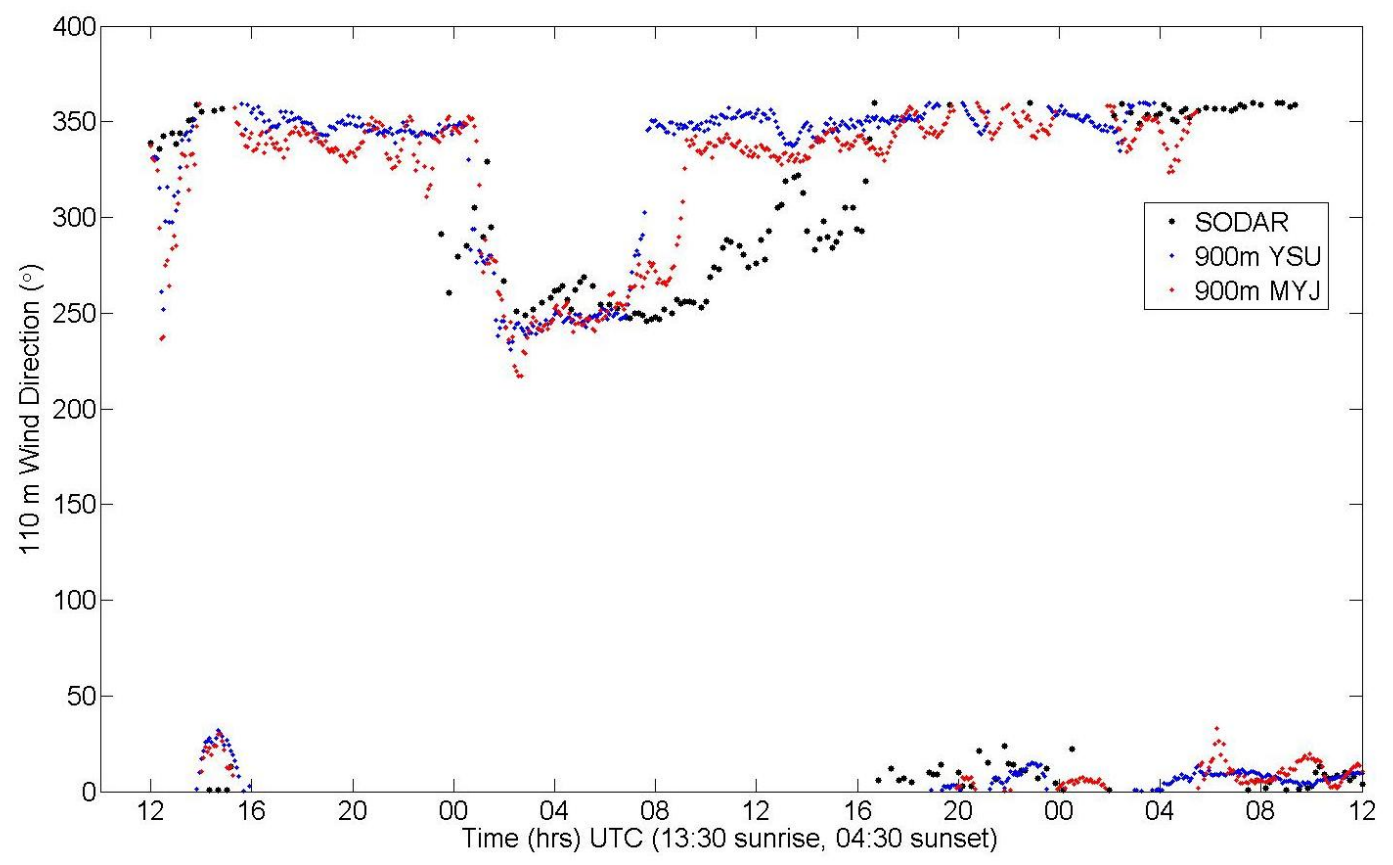

Figure 2.3: Wind direction at the $110 \mathrm{~m}$ height for the 900 meter horizontal resolution runs for Case S. Both PBL schemes incorrectly forecast the timing of the wind shift associated with the ramping event by predicting it too early. Interestingly, the $110 \mathrm{~m}$ and $180 \mathrm{~m}$ (Figure 2.2) SODAR observations do not show the wind direction shift clearly occurring during the ramping event (16 UTC on day 2 ) as is observed in the $60 \mathrm{~m}$ measurements.

\section{Wind Speed}

The incorrect timing of the ramp also appeared in the wind speed simulations as shown in Figures 2.4-2.6. The $900 \mathrm{~m}$ horizontal resolution is shown for the top of the rotor disk (110 m height) in Figure 2.4 and above the rotor disk (180 m height) in Figure 2.5, while the $8100 \mathrm{~m}$ resolution is shown for the lower half of the rotor disk (60 m height) in Figure 2.6. In contrast to wind direction which appeared to be more accurately forecasted at higher altitudes, wind speed was better modeled at the lower altitudes regardless of horizontal resolution. Also, unlike the wind direction simulations, wind speed RMSE values indicate that the YSU PBL scheme can be considered to slightly outperform the MYJ scheme (Table 2.2). Both schemes clearly capture the 
small wind speed peak at the beginning of the simulation (14 UTC on day 1) and then continue to have similarly shaped and timed curves at each height. Both the YSU and MYJ schemes showed that the simulations fail to accurately capture the ramping event (17 UTC on day 2). For example, as seen in Figure 2.4, the observed SODAR wind speeds during the ramping event were nearly twice as large as the simulated wind speeds at the $110 \mathrm{~m}$ height. Furthermore, the simulations near the top of the rotor disk $(110 \mathrm{~m})$ showed no sudden increase in wind speed as was seen in the observations during this time.

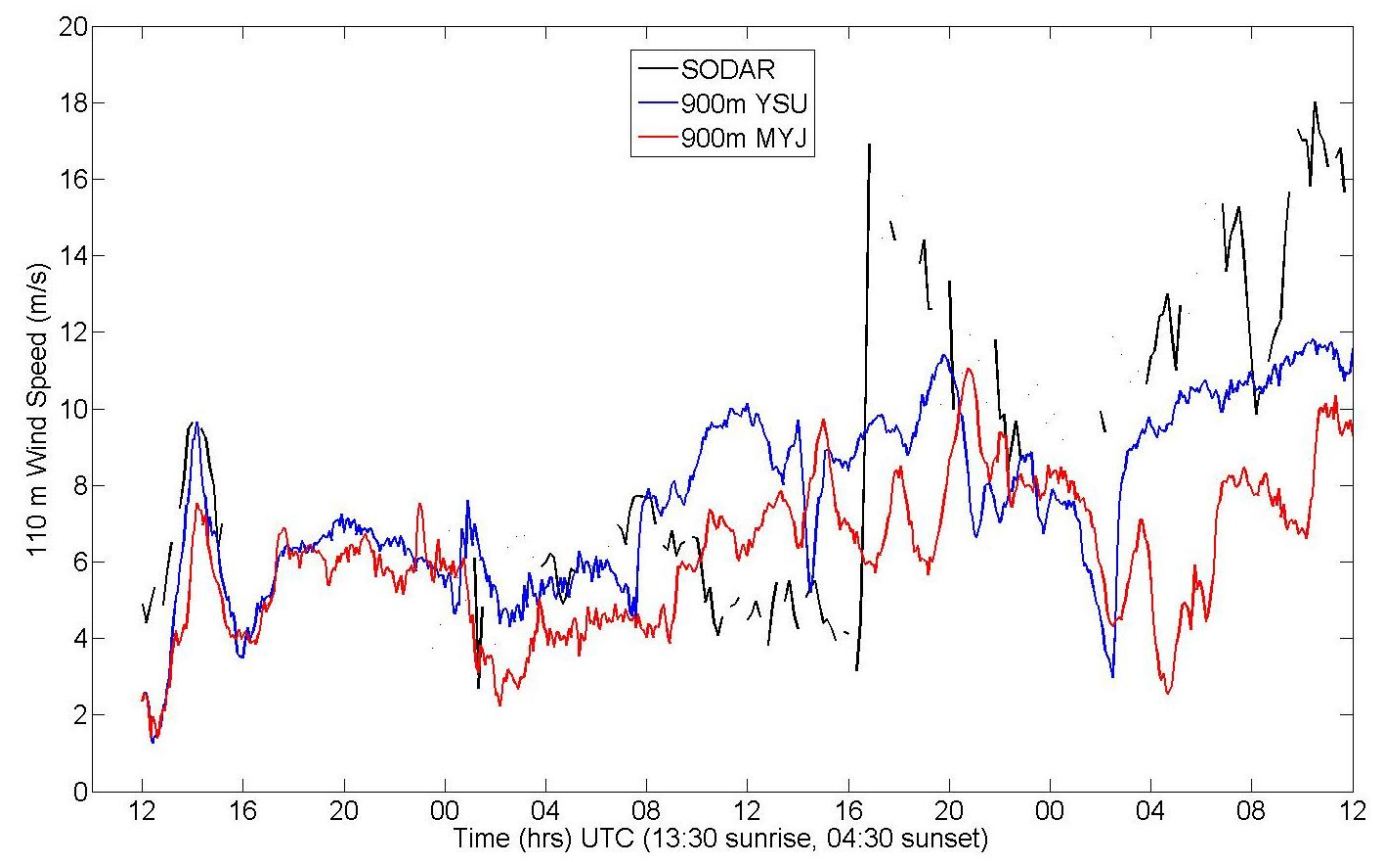

Figure 2.4: 110 meter wind speed from the 900 meter horizontal resolution runs for Case S. The ramp does not show up significantly in the models as compared to other simulated heights and horizontal resolutions. Both PBL schemes follow the same trend in wind speed prediction; each scheme under predicts the maximum ramping wind speed by an approximate factor of 2 .

Farther aloft, the MYJ scheme actually predicted a decrease in wind speed right around the time of the ramping event (17 UTC on day 2) and at this altitude, neither model appeared to 
capture the ramp (Figure 2.5). We conclude that the shape of the wind profile during the ramping event was particularly poorly represented by the model setup under consideration here. Wind shear is likely to affect wind turbine productivity (Antoniou et al., 2009; Wharton and Lundquist, 2010), and this failure of the forecasting model to not only capture the timing of the ramping event but also the shape of the profile of the winds during the ramping event is significant.

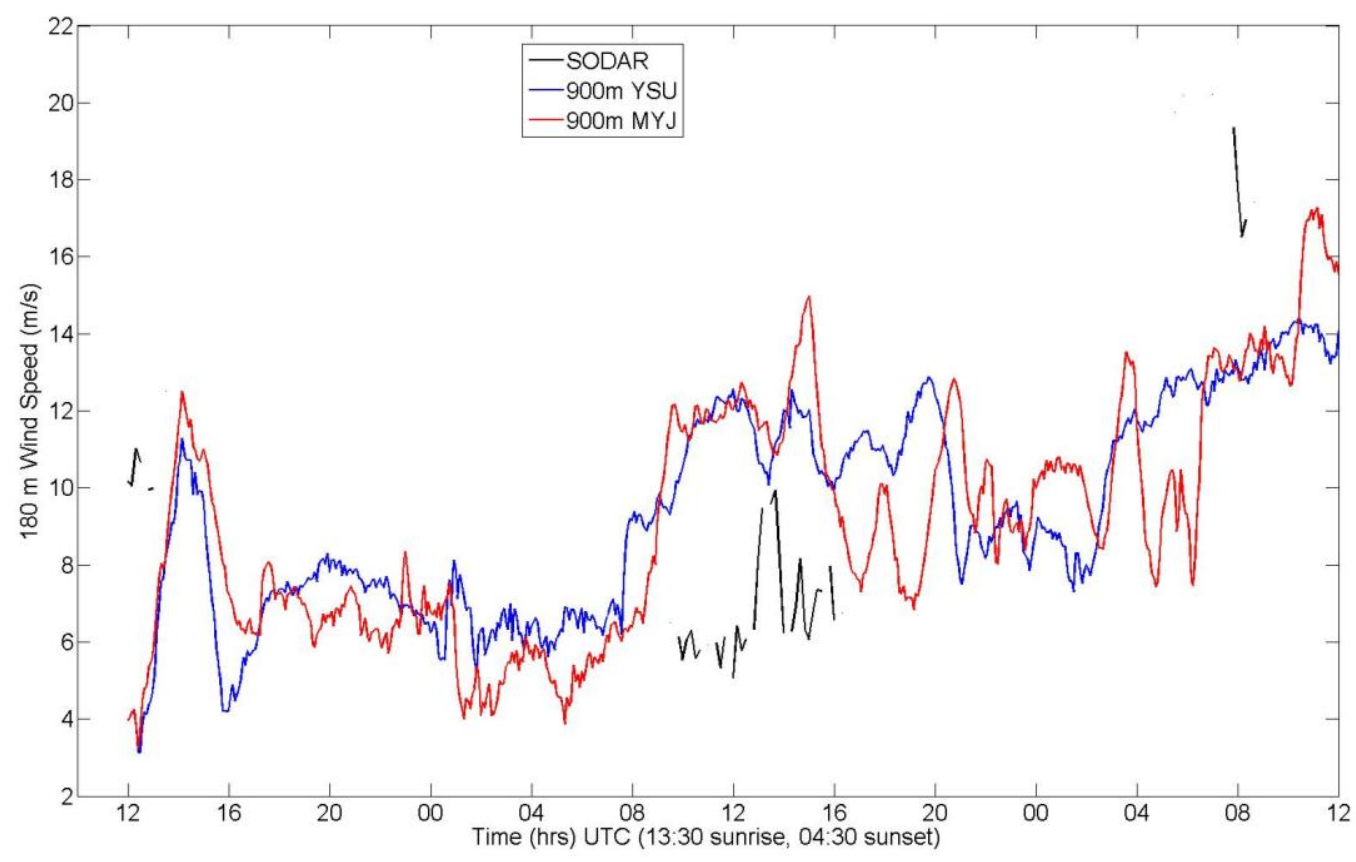

Figure 2.5: 180 meter wind speed from the $\mathbf{9 0 0}$ meter horizontal resolution runs for Case S. Both PBL schemes follow the same trend in wind speed prediction, including an over prediction of wind speed before the ramping event and an under prediction of wind speed after the ramp. Note that much of the SODAR data were missing at this altitude.

The improved performance from YSU was most clearly seen in the finest mesoscale simulation, at $900 \mathrm{~m}$ resolution, shown in Figure 2.4, in which the YSU forecast more closely agreed with the increased wind speeds later in the simulation. The $900 \mathrm{~m}$ resolution simulation 
shown in Figure 2.5 and the 8100 m resolution simulation shown in Figure 2.6 indicated that the modeled ramp occurred at approximately 08 UTC on the second day of the simulation and led the observed ramp, at approximately 17 UTC, by 9 hours. The choice of PBL schemes for wind speed forecasting is not clear as the $8100 \mathrm{~m}$ resolution run shows that the YSU scheme better captured the ramping event in Figure 2.6. Best model-observation agreement appeared at the lower horizontal resolution, with the YSU scheme, and for heights in the lower half of the rotor disk (Table 2.2).

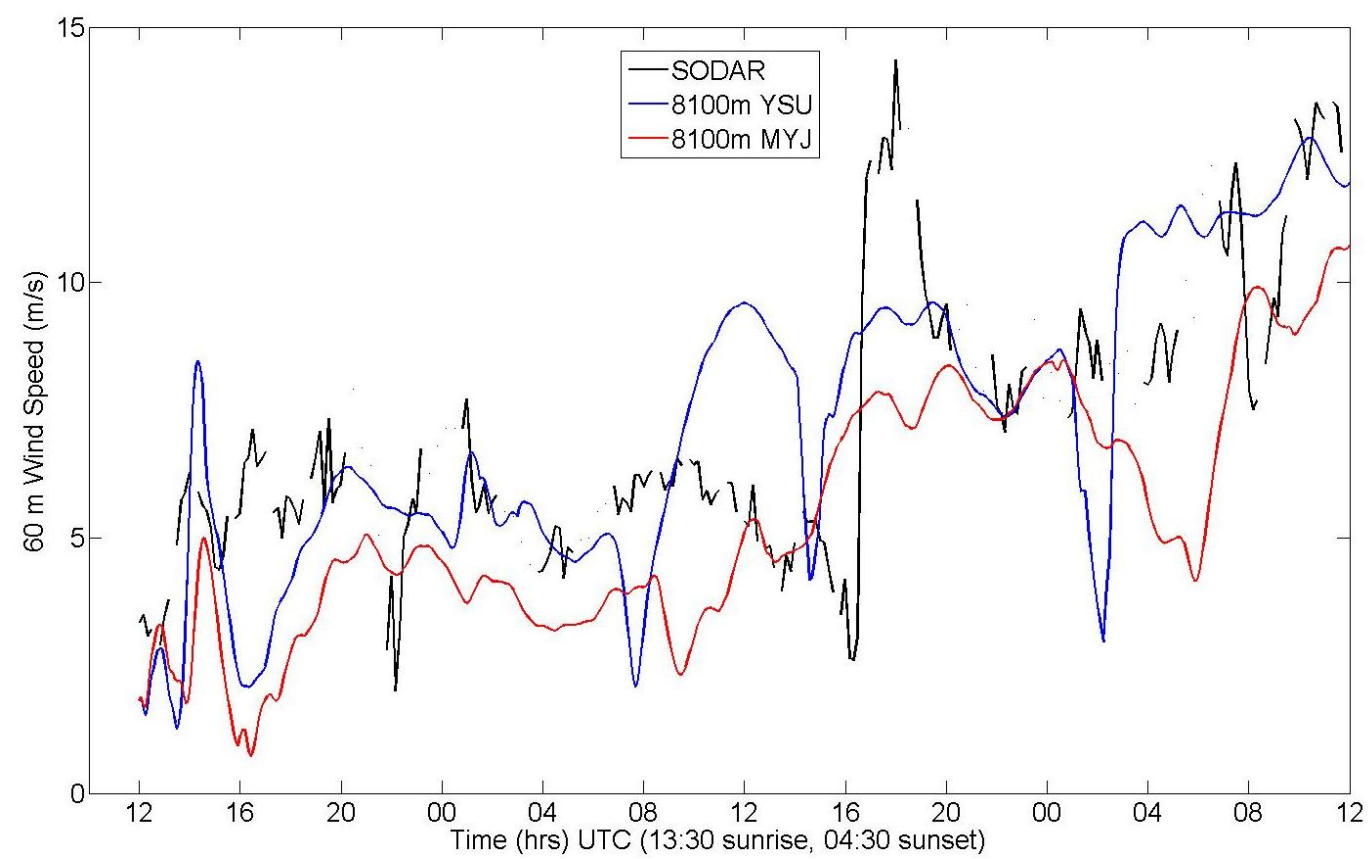

Figure 2.6: 60 meter wind speed from the 8100 meter horizontal resolution runs for Case S. The YSU PBL scheme predicts a ramp approximately 8 hours prior to the observed ramping event. These simulations show the best agreement between the forecasted wind speed and observations compared to runs with finer horizontal resolution and at higher heights.

\subsection{Conclusions}

In this study, we ran the wind ramp forecasting capabilities of the WRF model with minimal tuning of model parameters. No adjustments to default WRF settings were made other 
than a change to the PBL and surface-layer schemes. Standard vertical resolutions and products for boundary conditions and surface characterization were employed. These simulations are intended as a comparison to more sophisticated simulations carried out in Chapter 3 (WRF-LES) and Chapter 4 (PF.WRF) to emphasize the critical role of skilled model set-up rather than "outof-the-box" model execution.

It is clear that the performance of the model for this particular ramping event is suboptimal; the timing of the ramp was incorrectly forecast by up to nine hours by simulations with either the MYJ or YSU PBL scheme. Furthermore, increasing the horizontal resolution to the limit of the terrain resolution $(1 \mathrm{~km})$ did not universally improve the forecast. Instead, the YSU PBL scheme showed a slight advantage in predicting total horizontal wind speed during the ramping event, while MYJ showed better agreement for capturing the shift in wind direction. It appears that the finer resolution model runs are useful for capturing changes in wind direction; however, better agreement was found at coarser resolutions when modeling abrupt changes in wind speed. This evaluation is complicated by incomplete SODAR data availability, particularly at higher altitudes $(\sim 180 \mathrm{~m})$ during the ramping event; although, these heights are above the turbine rotor disk and do not directly determine wind power generation. The poor performance of the simulations presented here should not be considered an indictment of the capabilities of numerical weather forecasting for these applications, but rather as a warning of the importance of careful and skillful model set-up for each site of interest. 


\section{Chapter 3: WRF-LES}

WRF includes large-eddy simulation (LES) capabilities. This chapter examines three ramping events to develop preliminary insight into the ability of WRF-LES to capture sudden shifts in wind speed and power that are important to wind farm operators. Many studies over complex terrain point to increasing grid resolution as a means to achieving better agreement of simulations with observations (e.g., Gronas and Sandvik 1999, Grell et al. 2000). Higher grid resolution should be more important for locally-driven transitions. Errors in modeled wind speed can be due to errors in the representation of turbulent motions, as well as to sub-grid features in the topography and land use, as seen in the simulations of Hanna and Yang (2001). The effects of horizontal and vertical grid resolution, one-way vs. two-way nesting, turbulence closure models, and long term simulation results are examined here. Results are presented below, along with discussion of the numerical setup and grid nesting approaches.

\subsection{Numerical simulation setup}

\section{Grid nesting and topography}

Five one-way nested grids were used to simulate flow conditions for the wind farm at horizontal resolutions of $8.1 \mathrm{~km}, 2.7 \mathrm{~km}, 900 \mathrm{~m}, 300 \mathrm{~m}$, and $100 \mathrm{~m}$. The main features of the topography were visible at $2.7 \mathrm{~km}$, but fine structures became better resolved at $100 \mathrm{~m}$ resolution. Topography was extracted from a $10 \mathrm{~m}$ resolution data set available from the United States Geological Survey (USGS). The terrain was smoothed near the boundary for each nested sub-domain to match the elevations for the surrounding coarser grid. WRF uses a terrainfollowing, hydrostatic-pressure vertical coordinate system with the top of the model being a constant pressure surface. The vertical grid spacing is normally assigned by default by WRF, or 
it can be specified by the user to decrease spacing near the bottom of the model and stretch it to the top.

The minimum vertical grid spacing $\left(\Delta z_{\min }\right)$ at the surface, as well as the average spacing $\left(\Delta z_{\text {avg }}\right)$ values are listed in Table 3.1 for the grid configurations used. The domain height is approximately $13 \mathrm{~km}$ in all cases. As seen in Table 3.1, the horizontal spacing $(\Delta h)$ is uniform. Increases in spatial resolution require decreases in the model time-step $(\Delta t)$.

\begin{tabular}{|l|l|l|l|l|}
\hline$(\mathbf{n x}, \mathbf{n y}, \mathbf{n z})$ & $\boldsymbol{\Delta} \boldsymbol{h}(\mathbf{m})$ & $\boldsymbol{\Delta} \mathbf{z}_{\min }(\mathbf{m})$ & $\boldsymbol{\Delta} \mathbf{z}_{\text {avg }}(\mathbf{m})$ & $\boldsymbol{\Delta} \mathbf{t}(\mathbf{s})$ \\
\hline$(96,96,49)$ & 8100 & 35 & 246 & 30 \\
\hline$(96,96,49)$ & 2700 & 35 & 246 & 10 \\
\hline$(96,96,49)$ & 900 & 35 & 246 & 3.33 \\
\hline$(96,96,49)$ & 300 & 35 & 246 & 1.11 \\
\hline$(96,96,40)$ & 300 & 60 & 309 & 1.11 \\
\hline$(96,96,70)$ & 300 & 10 & 177 & 0.74 \\
\hline
\end{tabular}

Table 3.1: Simulation parameters for each grid level used in WRF-LES

\section{Initialization and lateral boundary conditions}

Initial and boundary conditions were obtained from the NCAR North American Regional Reanalysis (NARR) data. NARR is available at $32 \mathrm{~km}$ horizontal resolution at 29 vertical levels (1000-100 $\mathrm{hPa}$; excluding surface) to force the WRF simulations at the coarsest grid. Lateral boundary condition forcing was applied at three-hour intervals and linearly interpolated in between. Relaxation towards the lateral boundary values was applied around the edge of the domain. Simulations were performed for 48 hours for the ramping events and for 168 hours for the week-long statistical analysis. Output was stored at ten-minute intervals and used to generate initial and boundary conditions for the nested grids. 


\section{Surface characteristics}

WRF uses 33 land use categories (including ice and water) provided by the USGS. The simulations used National Land Cover Database (NLCD) data at $30 \mathrm{~m}$ resolution which was mapped from the native 19 land use categories to the USGS 33 land use categories. The Noah Land Surface Model was used with initial moisture and soil temperature in four layers provided by NARR. Land-atmosphere coupling effects on the boundary layer, such as soil moisture initialization, can have a significant effect on simulation results, and at finer resolutions it may be necessary to use finer-scale soil initialization fields (Chow et al. 2005, Woodward et al. 2009, Williams et al. 2009).

\section{Turbulence and computational mixing}

The standard Mellor-Yamada-Janjic scheme, which is appropriate for ReynoldsAveraged Navier-Stokes simulations, was used for the base case. Mellor-Yamada-Janjic (MYJ) is a one-dimensional prognostic turbulent kinetic energy scheme with local vertical mixing. A turbulent kinetic energy (TKE) closure of order 1.5 was used for the large-eddy-simulations performed. The TKE-1.5 model is useful in a LES context as long as the chosen length scale is proportional to the LES filter width, as it is in WRF. This closure is particularly useful for LES when a large fraction of the velocity scales are contained in the subfilter scales as with coarse resolution grids. A second LES closure, the Dynamic Reconstruction Model (DRM) (Chow et al. 2005) was also used in the simulations. DRM has been implemented into WRF (Mirocha et al. 2007) and is a "mixed model" which combines an eddy-viscosity component with a scalesimilarity component and has shown improved representation of turbulence in prior work (Chow et al. 2005, Chow and Street 2009). 


\subsection{Results}

Results comparing simulations with observations for the two-day ramping events and the week-long runs are given in this section. The synoptically-driven ramping event (Case $S$ ) in February was caused by a frontal passage just after significant precipitation and appeared 10 hours into the simulation ( 3 hours after sunrise) at which point wind speed magnitude increased from 3 to $15 \mathrm{~m} / \mathrm{s}$ over a 50 minute period. The locally driven ramping event (Case L) in July started 20 hours into the simulation (7 hours after sunrise) at which point the wind speed magnitude increased from 2 to $14 \mathrm{~m} / \mathrm{s}$ in just over 8 hours. A week-long simulation was performed for 7 days starting at the same time as the locally driven ramping event in July. Lastly, the effects of external forcing were examined for a locally-driven ramping event in May.

The naming convention for runs is “(finest horizontal resolution)_(number of points in vertical)", as shown in Table 3.2. All results are from one-way nesting and the Mellor-YamadaJanjic turbulence model unless otherwise noted.

\begin{tabular}{|c|c|}
\hline Run name & Configuration \\
\hline 300m_49 & base case simulation, 4 one-way nested grids \\
\hline 300m_70 & 4 one-way nested grids with 70 vertical levels \\
\hline $300 m \_40$ & 4 one-way nested grids with 40 vertical levels (chosen by WRF) \\
\hline 300m_49_2way & 4 two-way nested grids \\
\hline $900 m \_49$ & 3 one-way nested grids \\
\hline $2700 m \_49$ & 2 one-way nested grids \\
\hline $8100 m \_49$ & single grid \\
\hline 300m_49_TKE1.5 & 4 one-way nested grids, with TKE1.5 closure on the finest grid \\
\hline 900m_49_TKE1.5 & 4 one-way nested grids, with TKE1.5 closure on the finest grid \\
\hline 100m_49_TKE1.5 & 5 one-way nested grids, with TKE1.5 closure on the finest grid \\
\hline 100m_49_DRM1 & 5 one-way nested grids, with DRM closure at reconst. level 1 on the finest grid \\
\hline
\end{tabular}

Table 3.2: Naming convention and configurations used in the WRF-LES simulations. 


\section{Effects of horizontal resolution}

The effect of horizontal resolution was investigated to determine its significance in simulating both Case S (synoptically-induced) and Case L (locally-driven) ramping events. We compare output from one-way nested runs to evaluate the impact of grid resolution. SODAR observations of the evolution of wind speed and wind direction $30 \mathrm{~m}$ above the surface during the ramping event are presented in Figure 3.1 (left) for Case $\mathrm{S}$ and at $90 \mathrm{~m}$ in Figure 3.1 (right) for Case L (heights chosen are different due to observational data gaps). The observations are compared to one-way nested run resolutions: 300m_49 (4 grid nests), 900m_49 (3 grid nests), 2700m_49 (2 grid nests), and 8100m_49 (1 grid). Regardless of resolution, the simulation for Case $\mathrm{S}$ showed an increase in wind speed associated with this ramp that is slightly more gradual than was observed by the SODAR. The simulation for Case L also showed a more gradual increase in wind speed associated with the ramping event and did not capture the minimum wind speeds observed by the SODAR.

Figure 3.2 shows vertical profiles of the two ramping events. In general, the simulations better captured the wind speed after ramping rather than right before it. SODAR data were available at $10 \mathrm{~m}$ intervals from $20-200 \mathrm{~m}$ above ground level, however at elevations above 100 $\mathrm{m}$ there is usually less data available. Figure 3.3 shows the vertical structure of the atmosphere in time for the simulations interpolated to the SODAR's vertical levels. Case L over predicted wind speeds after the first 16 hours of the simulation and under predicted before the 16 hours, while Case S appeared to predict wind speeds more closely to the SODAR. 



Figure 3.1: Time series of wind speed for (left) Case S at $30 \mathrm{~m} \mathrm{AGL}$ and (right) Case L at $90 \mathrm{~m}$ AGL for the different horizontal resolutions. Better model agreement with the observations is found for the synoptic case.
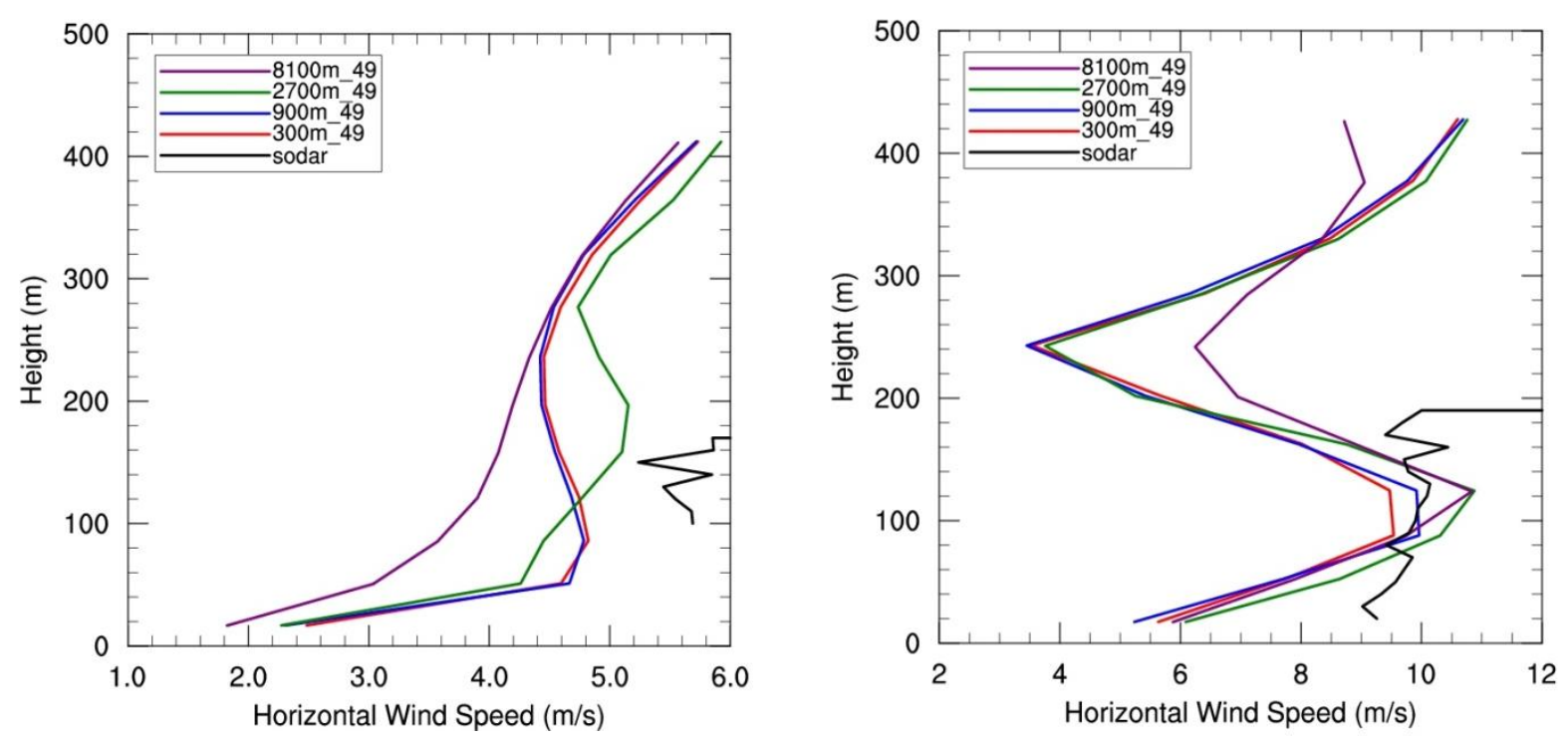

Figure 3.2: Vertical profiles of wind speed for (left) Case $S$ and (right) Case $L$ at a single time slice. Reasonable agreement is found for the local case at heights in the rotor-disk (40-120 $\mathrm{m})$. Poor agreement is found during the synoptic case although data recovery below $100 \mathrm{~m}$ is very low for this particular time slice. 

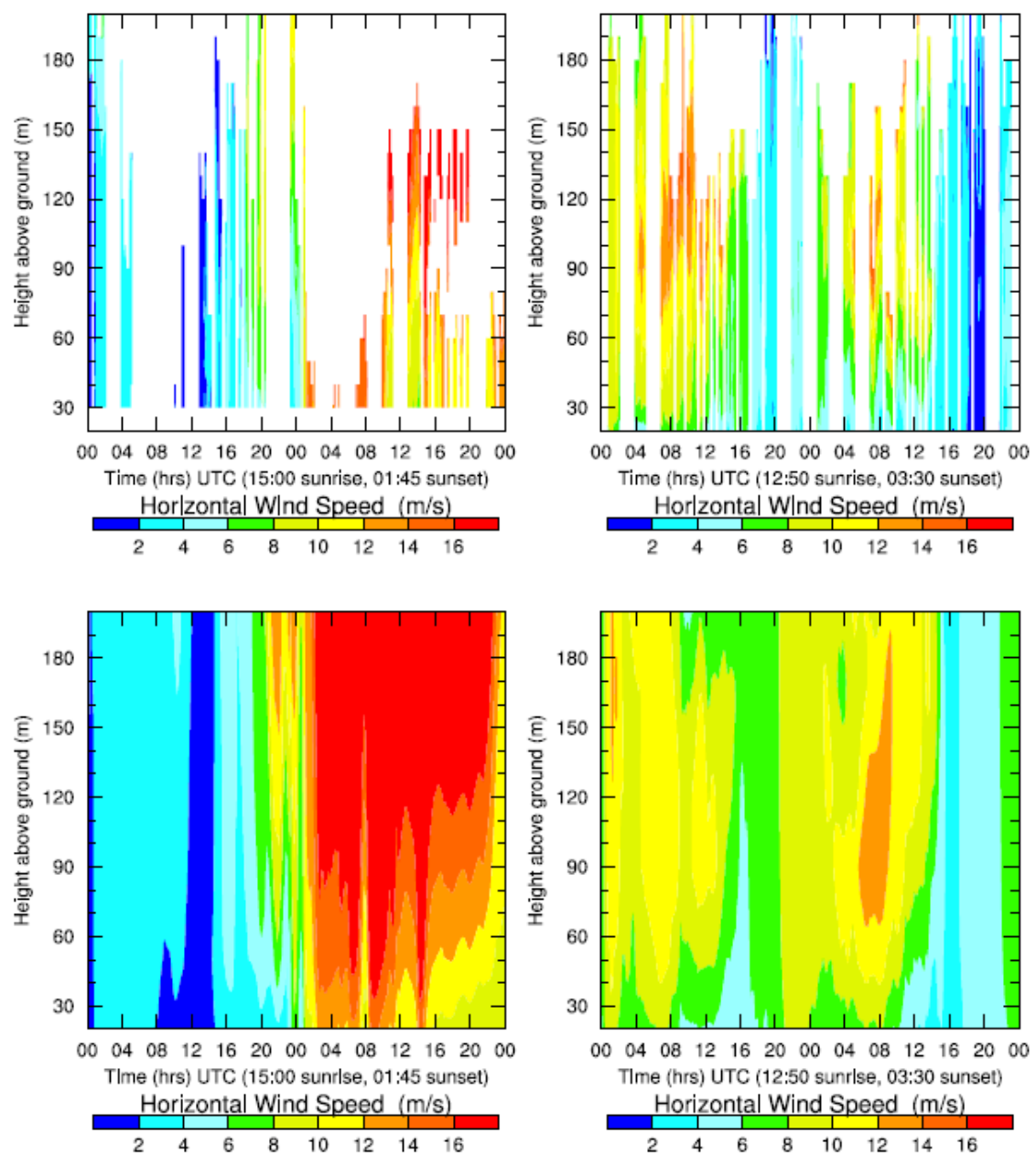

Figure 3.3: Contour plots showing a time series of wind speed as a function of height for Case $S$ (bottom left) and Case L (bottom right) compared to the SODAR observations (top row). Red indicates higher wind speeds; blue lower wind speeds. Good agreement is found between the simulated synoptic ramping event and the SODAR observations (left column).

To further quantify the comparison, Table 3.3 shows the root mean square errors (RSME) and mean absolute errors (MAE) between the SODAR data and the simulations over 0-200 $\mathrm{m}$ above the ground, averaged over 48 hours. They are defined as:

$$
\begin{aligned}
& M A E=\frac{1}{M} \sum_{j=1}^{M} \frac{1}{N} \sum_{i=1}^{N}\left|A_{i, j}-B_{i, j}\right| \\
& R M S E=\sqrt{\frac{1}{M} \sum_{j=1}^{M} \frac{1}{N} \sum_{i=1}^{N}\left(A_{i, j}-B_{i, j}\right)^{2}}
\end{aligned}
$$


where $\mathrm{M}=$ number of time steps, $\mathrm{N}=$ number of vertical grid points, $\mathrm{A}=$ observation, and $\mathrm{B}=$ simulation data. The difference between the errors for the various grid resolutions was not significant, as seen in the error metrics listed in Table 3.3. In fact, the results were very similar across all resolutions with the finest resolution producing a slightly larger error than the two finer ones preceding it. While all the runs captured the increase in wind speed during the ramping event itself, Case S appeared to be better captured and with less error than Case L. Under these particular conditions the relatively coarse horizontal resolution $(2.7 \mathrm{~km})$ appears to be ideal in capturing the shift in wind speed at the wind turbine hub heights $(\sim 80-100 \mathrm{~m})$ for both Cases $\mathrm{S}$ and L.

\begin{tabular}{|l|l|l|l|l|}
\hline & \multicolumn{2}{l|}{$\begin{array}{l}\text { Synoptically-driven } \\
\text { (S) case }\end{array}$} & \multicolumn{2}{l|}{$\begin{array}{l}\text { Locally-driven (L) } \\
\text { case }\end{array}$} \\
\hline Resolution & MAE & RMSE & MAE & RMSE \\
\hline 300 m_49 & 1.67 & 2.30 & 2.08 & 2.54 \\
\hline 900 m_49 & 1.62 & 2.23 & 2.05 & 2.48 \\
\hline 2700 m_49 & 1.63 & 2.16 & 2.01 & $\mathbf{2 . 4 7}$ \\
\hline 8100 m_49 & 1.77 & 2.30 & 2.23 & 2.69 \\
\hline
\end{tabular}

Table 3.3: Mean absolute error and root mean square error for simulated versus observed wind speed at different horizontal resolutions. Lowest RMSE for each case are in bold.

\section{Effects of vertical resolution}

Vertical spacing may have a significant effect on the accuracy of predictions of wind speed and direction when wind shear is strong, e.g., in the case of a nocturnal low level jet which is often responsible for ramping events in the Midwest, USA (e.g., Storm et al. 2009). The vertical grids tested here using 4 one-way nesting levels were generated as follows: 300m_49 uses a tanh function to stretch the vertical grid spacing so that there is smaller spacing closer to the ground; 300m_70 uses specified grid levels that provide spacing of about $10 \mathrm{~m}$ in the lowest $200 \mathrm{~m}$ of the atmosphere and then stretched; 300m_40 was created by specifying 40 levels in 
WRF and using the default spacing (the minimum spacing was $60 \mathrm{~m}$ and average spacing was $309 \mathrm{~m}$ ). Figure 3.4 shows the evolution of the wind speed and Table 3.4 shows the RMSE and MAE between simulations and observations along with the average vertical spacing in the range of the observation data (20-200m AGL). The grids gave similar results for these ramping events. The finely spaced vertical resolution was marginally better at capturing the ramping event than the coarse WRF defined levels. The tanh spaced 49 level simulation performed slightly better than the others in both ramping events, although only by $\sim 0.04 \mathrm{~m} / \mathrm{s}$. The less computationally intense option appears adequate for predicting these ramps.
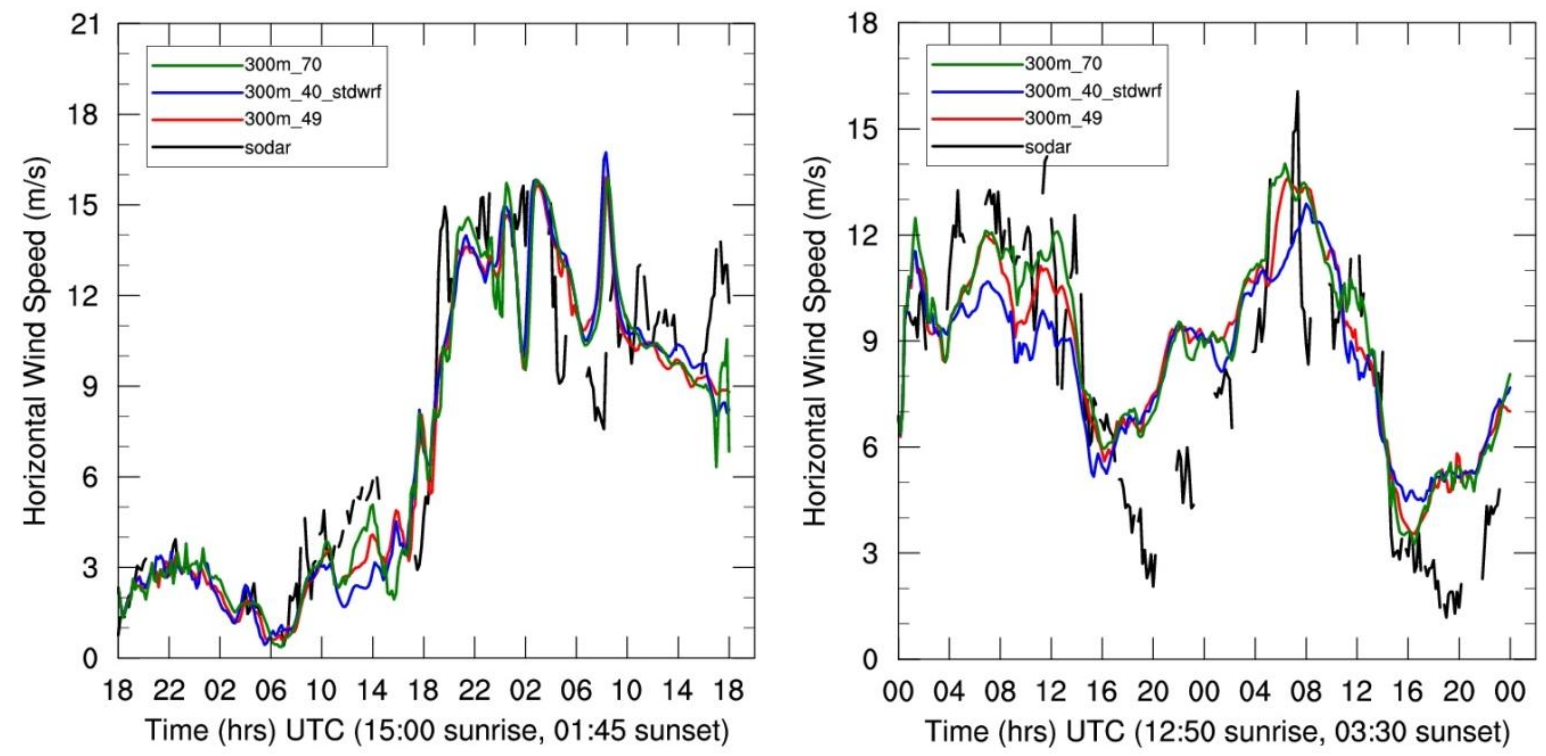

Figure 3.4: Time series of wind speed for (left) Case $S$ and (right) Case L for the different vertical resolutions. The timing of the ramping event is well predicted in the synoptic case regardless of the user-defined vertical spacing.

\begin{tabular}{|l|l|l|l|l|}
\hline & \multicolumn{2}{|l|}{$\begin{array}{l}\text { Synoptically-driven } \\
\text { (S) case }\end{array}$} & \multicolumn{2}{l|}{ Locally-driven (L) case } \\
\hline Resolution & MAE & RMSE & MAE & RMSE \\
\hline 300m_49 & 1.67 & 2.30 & 2.08 & 2.54 \\
\hline 300m_40_stdwrf & 1.73 & 2.39 & 2.07 & 2.59 \\
\hline 300m_70 & 1.72 & 2.33 & 2.07 & 2.55 \\
\hline
\end{tabular}

Table 3.4: Mean absolute error and root mean square error for simulated versus observed wind speed at different vertical spacing. Lowest RMSE for each case are in bold. 


\section{Difference between 1-way and 2-way nesting}

With two-way nesting, the finer grid feeds back information to the coarser parent domain, thus updating the coarser grid with higher resolution fields and theoretically leading to a more accurate simulation result. In one-way nesting, the finer domains do not influence the parent domains at all. Two-way nesting is thought to be important when fine-scale features that are resolvable on the finer domain affect meteorological conditions on a larger scale. Under strong synoptic-scale forcing, it is likely that one-way nesting will be adequate for feeding information from the larger scales to the finer scales. This also seemed to be the case for the Case L (locallydriven forcing) as Figure 3.5 shows, likely because of the simplicity of the topography. Figure 3.5 shows the time series of wind speed for the 1-way nested base case, $300 \mathrm{~m} \_49$, and the 2-way nested 300m_49_2way, each with the same four nesting levels. Table 3.5 shows the MAE and RMSE between simulations and observations. There was no significant difference here between 1-way and 2-way nesting compared to observations for both Cases $\mathrm{S}$ and $\mathrm{L}$.
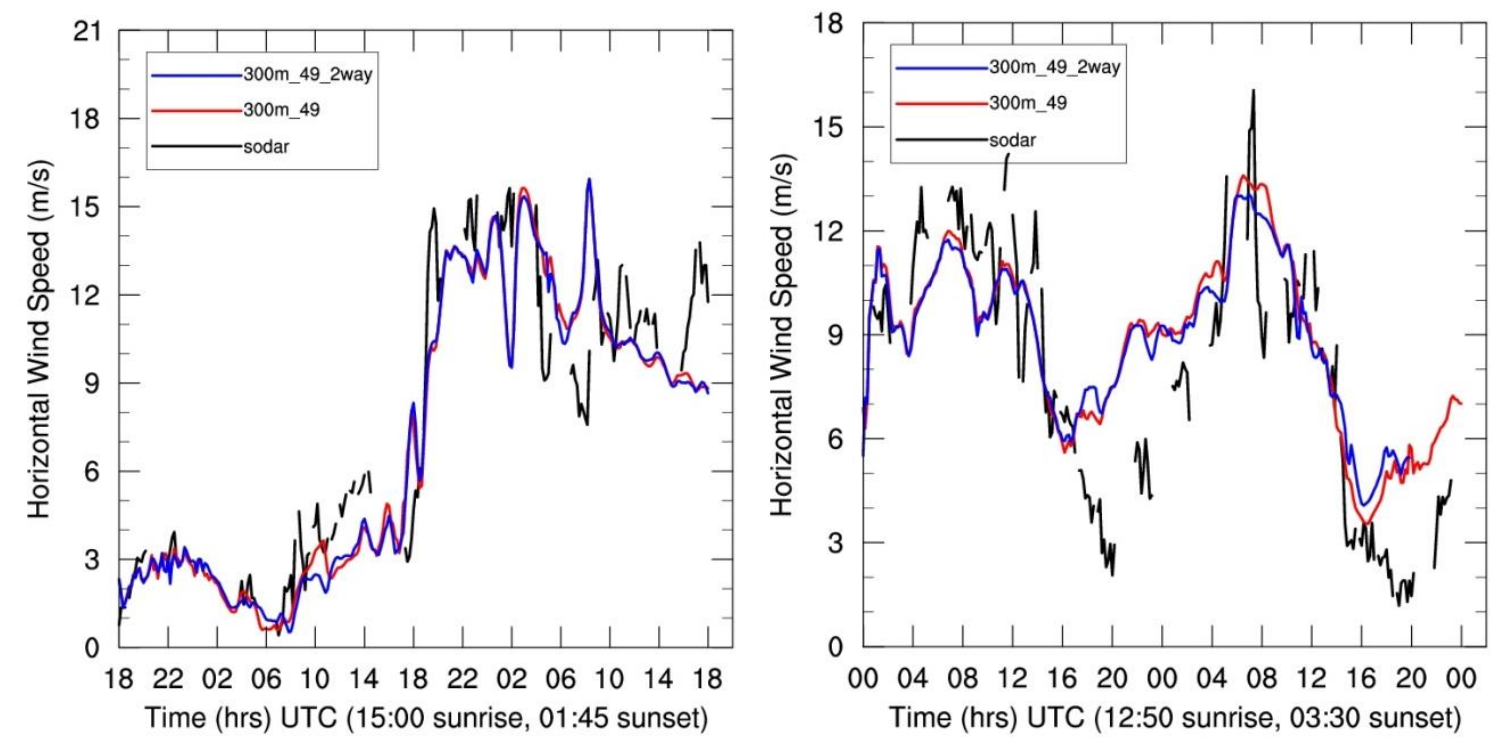

Figure 3.5: Time series of wind speed time comparing nesting configurations (one-way versus two-way) for (left) Case $S$ (February) and (right) Case L (July). No significant improvement is seen with the 2-way nesting. 


\begin{tabular}{|l|l|l|l|l|}
\hline & \multicolumn{2}{|l|}{$\begin{array}{l}\text { Synoptically-driven } \\
\text { (S) case }\end{array}$} & \multicolumn{2}{l|}{$\begin{array}{l}\text { Locally-driven (L) } \\
\text { case }\end{array}$} \\
\hline Resolution & MAE & RMSE & MAE & RMSE \\
\hline 300m_49 & 1.67 & $\mathbf{2 . 3 0}$ & 2.08 & 2.54 \\
\hline 300m_40_2way & 1.68 & 2.31 & 2.07 & $\mathbf{2 . 5 2}$ \\
\hline
\end{tabular}

Table 3.5: Mean absolute error and root mean square errors for wind speed comparing oneway versus two-way nesting for the ramping events. Lowest RMSE for each case are in bold.

\section{Comparing RANS to LES closures}

At horizontal resolutions finer than $1 \mathrm{~km}$, it may be beneficial to transition to a largeeddy simulation closure within a nested simulation framework. WRF's standard LES closure is the TKE 1.5 scheme. We performed simulations using the TKE 1.5 turbulence model for the finest domain level (with the coarser grids using Mellor-Yamada-Janjic) and compared to the Mellor-Yamada-Janjic model at all nesting levels. Both runs were 1-way nested because simulations with TKE 1.5 are unstable for 2-way nesting in this case (see discussion in Moeng et al. 2007). Figure 3.6 shows the TKE 1.5 model at different resolutions compared to the base case. Surprisingly our base case provided the best comparison to observation results. The TKE 1.5 closure tended to over predict the wind speeds in both ramping cases even at the finest resolution of $100 \mathrm{~m}$. The results significantly improved for TKE 1.5 with finer resolution but are not better than the base case, as shown in Table 3.6.

Figure 3.7 shows how DRM level 1 compared to TKE 1.5 and the base case. The DRM closure did not show any improvement over the TKE 1.5 scheme at the same level. In WRF, the TKE 1.5 closure does not perform well with diffusion during the presence of strong heat fluxes for coarser grids as it uses an explicit scheme for calculating the diffusion. This is a possible reason that the TKE 1.5 closures do not perform as well at coarser resolutions. The overprediction in wind speed decreased with finer resolution, until $100 \mathrm{~m}$ when it closely matched the 
estimates of the $300 \mathrm{~m}$ MYJ run. There was no great benefit in using LES at these fine scales because the finest grid relies on and is influenced by the RANS parent domains, which limit the fine grid's ability to vary from the parent.


Figure 3.6: Wind speed for (left) Case $S$ and (right) Case L for TKE1.5 closure at the different horizontal resolutions. The base case provides the highest model-observation agreement.
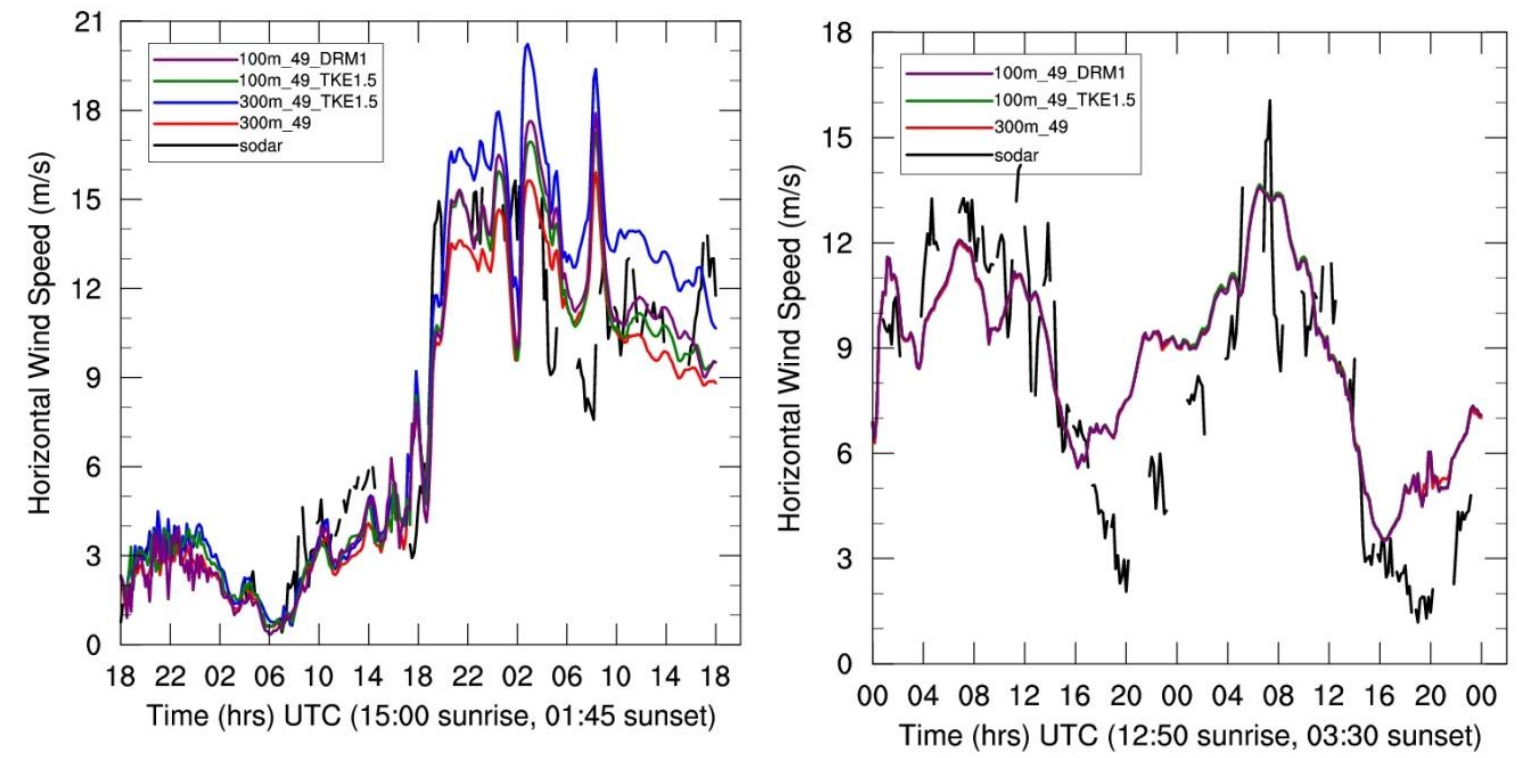

Figure 3.7: Wind speed for (left) Case $S$ and (right) Case L comparing DRM with the TKE 1.5 LES closures. The DRM closure fails to show improved accuracy in forecasting ramps. 


\begin{tabular}{|l|l|l|l|l|}
\hline & \multicolumn{2}{|l|}{$\begin{array}{l}\text { Synoptically-driven } \\
\text { (S) case }\end{array}$} & \multicolumn{2}{l|}{$\begin{array}{l}\text { Locally-driven (L) } \\
\text { case }\end{array}$} \\
\hline Resolution & MAE & RMSE & MAE & RMSE \\
\hline 300m_49 & 1.67 & $\mathbf{2 . 3 0}$ & 2.08 & $\mathbf{2 . 5 4}$ \\
\hline 900m_49_TKE1.5 & 4.01 & 5.51 & -- & - \\
\hline 300m_49_TKE1.5 & 2.29 & 3.14 & 3.54 & 4.09 \\
\hline 100m_49_TKE1.5 & 1.73 & 2.43 & 2.10 & 2.56 \\
\hline 100m_49_DRM1 & 1.73 & 2.44 & 2.08 & $\mathbf{2 . 5 4}$ \\
\hline
\end{tabular}

Table 3.6: Mean absolute error and root mean square error for ramping events comparing LES turbulence closure schemes with the base case (300m_49). Lowest RMSE for each case are in bold. Overall, the base case provides the highest model-observation agreement.

\section{Comparing resolution with week-long simulations}

A week-long simulation was performed for seven days starting on the same day as the locally-driven test case in July. The goal was to determine if grid resolution affects predicted disturbances of wind speed and turbulence intensity distributions for the wind farm. Changes in long-term distributions could enable more detailed site evaluations for turbine placement during wind farm development.

The results obtained from running week-long simulations for horizontal wind speeds agreed with the shorter term 48 hour simulations. The finer resolution runs showed little variation from the coarser resolutions as shown in the probability density function (PDF) in Figure 3.8. A PDF was created for the $90 \mathrm{~m}$ height wind speed and binned into 18 equally spaced bins that spanned the minimum and maximum range for each category at the SODAR location. The model simulations tend to under predict the frequency of wind speeds above $12 \mathrm{~m}$ $\mathrm{s}^{-1}$ and over predict the frequency of wind speeds between 3 (cut-in speed) and $11 \mathrm{~m} \mathrm{~s}^{-1}$. Overall, the PDFs show, along with the SODAR observations, that during this week in summer, wind speeds were high and favorable for producing wind energy at the site. 


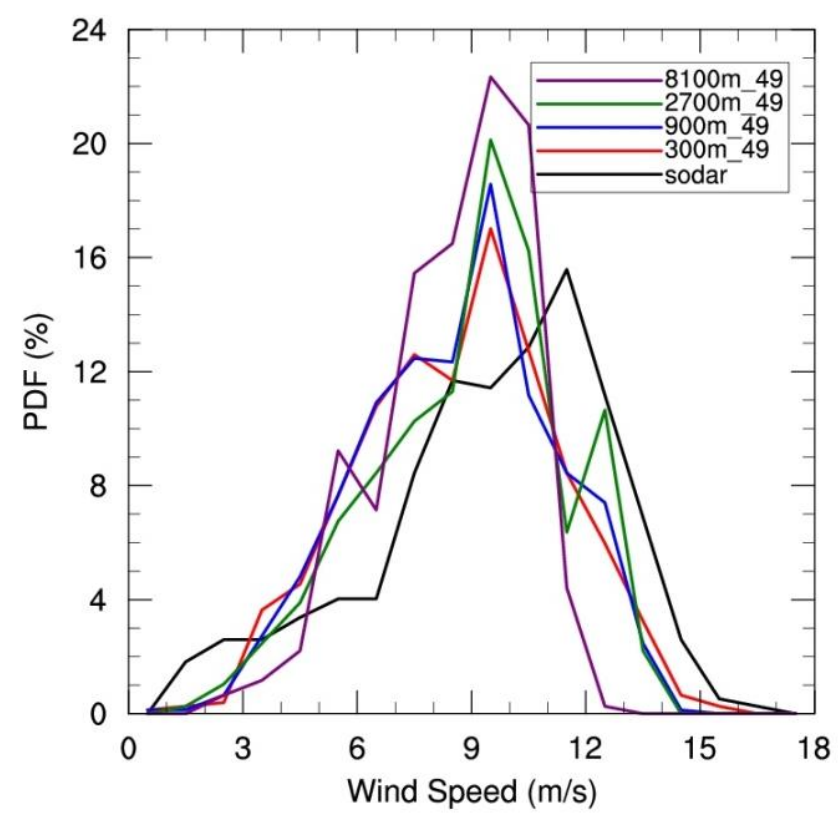

Figure 3.8: Probability distribution function for observed and simulated wind speeds during the one week-long period in July (Case L). The observations are skewed towards a higher frequency of wind speed above $12 \mathrm{~m} / \mathrm{s}$ than predicted by the model s.

Turbulence intensity is important because at very high magnitudes the wind turbines will need to be switched off in order to avoid structural damage. Turbulence intensity is also vital to consider in determining potential wind farm locations. It is not adequate for a site to only have high wind speeds; it should have tolerable levels of turbulence intensity as well, otherwise the turbines will be offline for most of the day(s). The definition of turbulence intensity is:

$T I=\frac{\sqrt{\sigma_{u}^{2}+\sigma_{v}^{2}+\sigma_{w}^{2}}}{U_{\text {mean }}}$

where $T I$ is turbulence intensity, $U_{\text {mean }}$ is the average total speed over a time period, $\sigma_{u} ; \sigma_{v} ; \sigma_{w}$ are the standard deviations of wind speed over that same time period in the East-West, North-South, and vertical directions respectively. The turbulence intensity for the SODAR was calculated by averaging the wind speed at every recorded second over a 10 minute period and calculating the 
standard deviation of each component of horizontal wind speed. The turbulence intensity for the simulations was calculated using WRF's output of TKE for MYJ:

$T I=\frac{\sqrt{T K E}}{U}$

where TKE is the WRF output of turbulent kinetic energy for a specific time step and $U$ is the total speed at the same time step. As Figure 3.9 shows, there was not a large difference between the different resolutions as they matched up to the SODAR. The simulations showed similar results and had similar probability densities as the SODAR. The peaks for the turbulence intensity were slightly skewed, with the simulations predicting slightly lower turbulence intensity when compared to the SODAR. However, as the number of bins increased the differences in skewness were reduced.

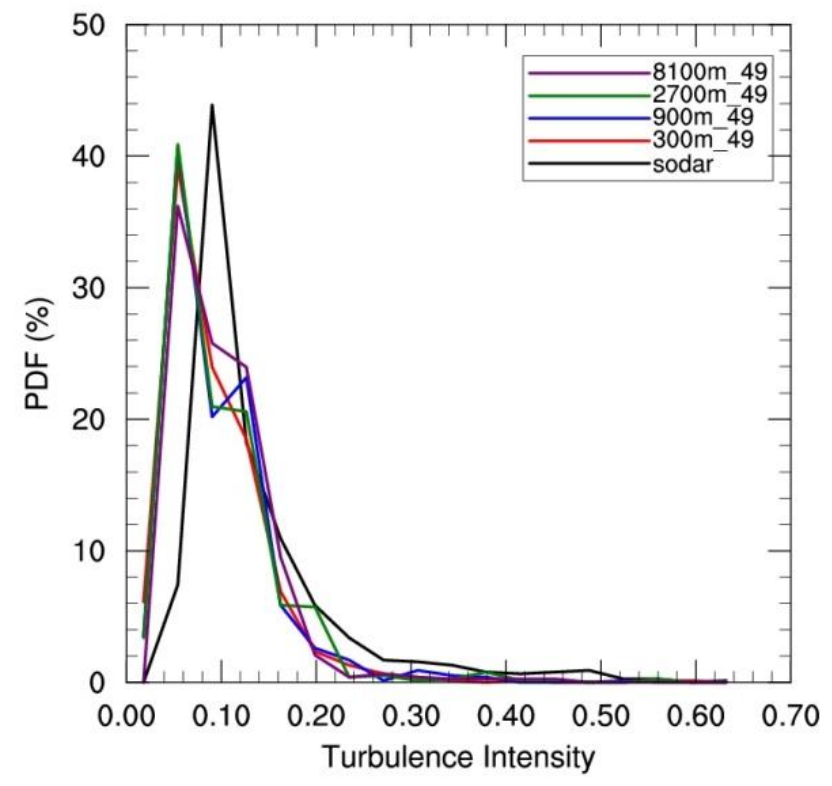

Figure 3.9: Probability distribution function for observed and simulated turbulence intensity during the one week-long period in July (Case L). At this site, turbulence intensity exceeded $20 \%$ less than $4 \%$ of the week. 


\section{Topographic resolution analysis}

A potential explanation for why the simulations showed little change with higher resolutions is that the terrain of the wind farm is comprised of rolling hills with less than $120 \mathrm{~m}$ in elevation gain. Thus even the coarsest simulations used here were able to adequately capture the terrain. Figure 3.10 shows that the resolutions, fine and coarse (except for the $8100 \mathrm{~m}$ case), capture the hills and general topography of the wind farm quite well. The coarsest domain (8.1 $\mathrm{km})$ was the least effective at capturing the terrain and showed the greatest errors in the simulations discussed above.

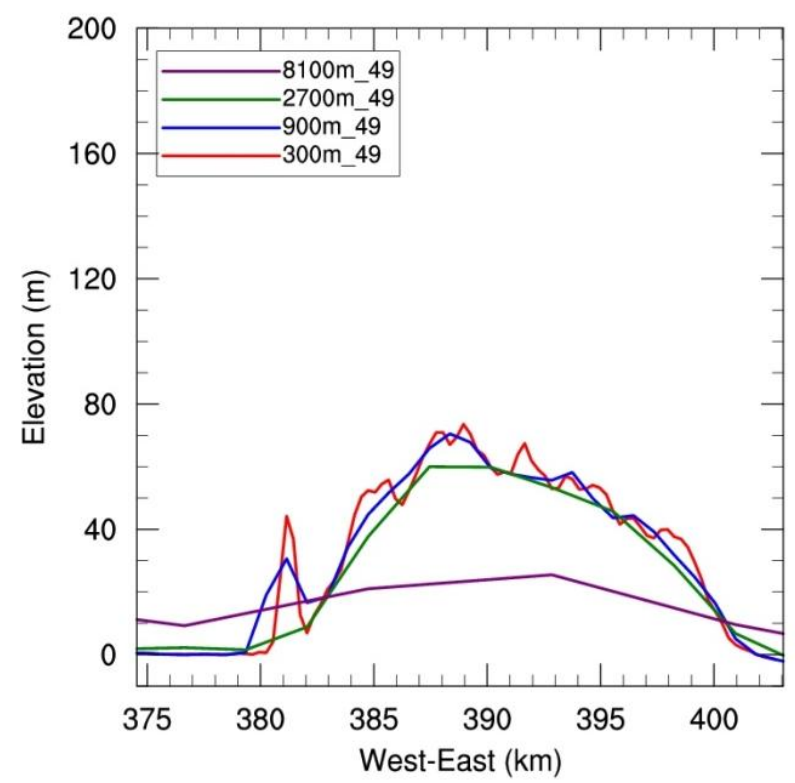

Figure 3.10: The terrain is well resolved by all but the coarsest horizontal resolution.

\section{Land surface conditions and effects on results}

Here we examine the effect of land surface forcing on the ramping event for Case L. Sensitivity tests were designed to test the role of soil moisture in these ramping events. In general, Case L was anticipated to be more sensitive to land-surface forcing. This is because Case L occurred during May, a period of large differential heating between the interior land and 
Pacific Ocean. Case L ramping event showed greater errors when compared to SODAR observations than Case S, especially in capturing the ramping at hub height. This indicates that there is room for improvement in the simulations. Figure 3.11 (top) shows that when the soil is initialized as dry, 300m_49_2way_dry, the results matched our base case fairly well by capturing the SODAR observations during peak wind speeds. The opposite was true for the saturated soil run, 300m_49_2way_sat. The simulation improved the capture of the minima wind speeds following the ramping event, but was out of phase with the maxima. Over the entire simulation, the saturated case showed reduced error when compared to the base and dry cases (Table 3.7). Figure 3.11 (middle and bottom) shows that a $3^{\circ} \mathrm{K}$ difference in potential temperature or a 0.004 $\mathrm{kg} / \mathrm{kg}$ difference in water vapor mixing ratio in the atmosphere leads to drastic changes in wind speed as shown in Figure 3.12. Replicating the proper land-surface conditions might be more important in capturing the locally-driven ramp than looking at differences in resolution or choice of turbulence closure. This suggests the importance of considering many parameters in a simulation, apart from resolution and turbulence closures, such as land surface models and soil moisture initialization, as these choices may yield less error in capturing the ramping event.

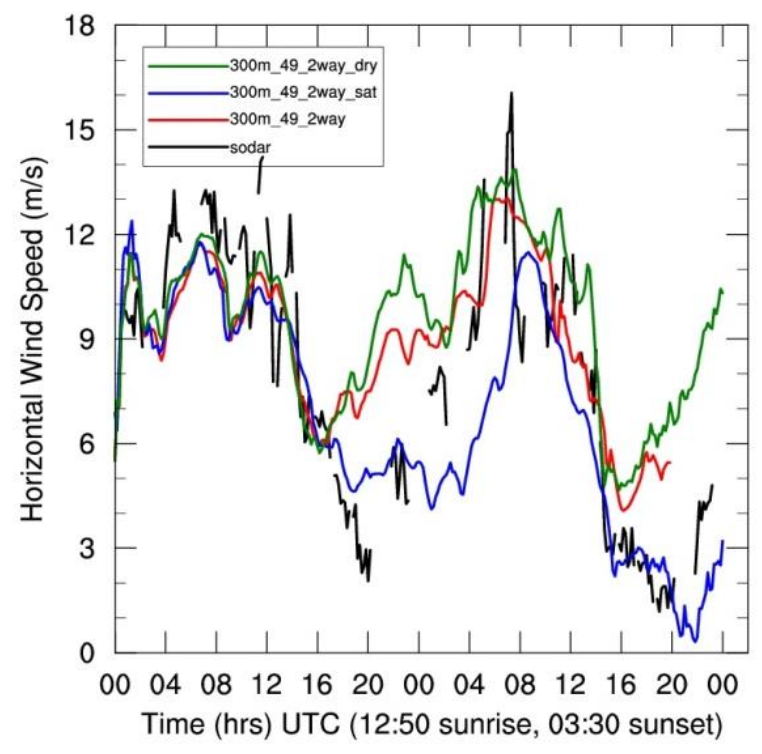



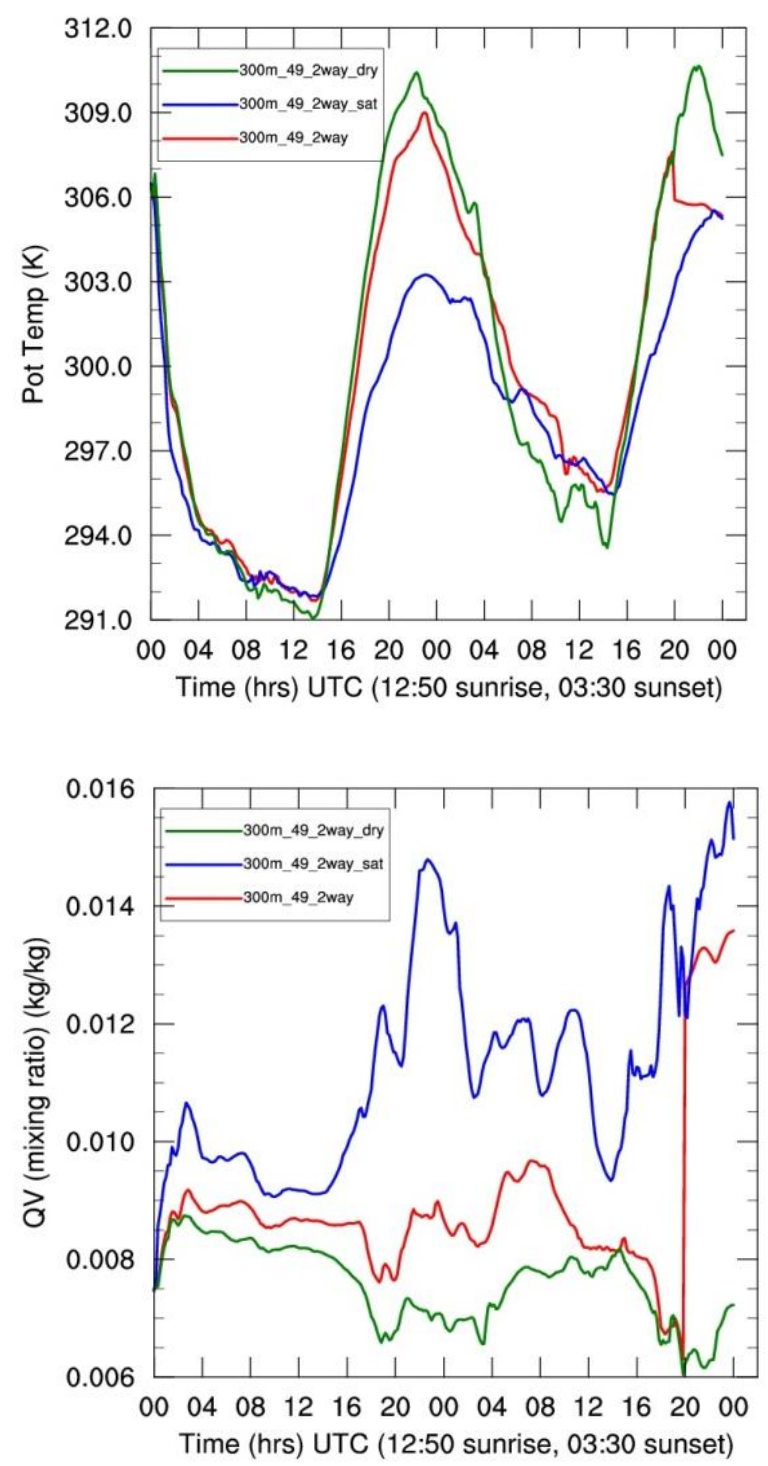

Figure 3.11: Land-surface variations for wind speed (top), potential temperature (middle), and water vapor mixing ratio (bottom) at $90 \mathrm{~m}$ above ground. Note that SODAR does not measure temperature or mixing ratio.

\begin{tabular}{|l|l|l|}
\hline & \multicolumn{2}{l|}{$\begin{array}{l}\text { Locally-driven (L) } \\
\text { case }\end{array}$} \\
\hline Resolution & MAE & RMSE \\
\hline 300m_49_2way & 2.07 & 2.52 \\
\hline 300m_49_2way_sat & 1.62 & $\mathbf{2 . 1 0}$ \\
\hline 300m_49_2way_dry & 2.66 & 3.24 \\
\hline
\end{tabular}

Table 3.7: Mean absolute error and root mean square error for Case $L$ for different landsurface conditions (control, saturated, dry). Lowest RMSE is in bold. 



Figure 3.12: Contour plots showing wind speed as a function of height for the Case L Day comparing SODAR observations (top left) to the simulated base case (top right), dry case (lower left) and saturated case (lower right).

\section{The effects of external forcing}

Lastly, the source of initial and boundary condition data may significantly affect simulation results and should also be considered. Figure 3.13 shows how two different sets of external forcing data led to very different results for a locally-driven ramping event in May. 
When the base case (300m_49) with NARR forcing was run, the ramping event was forecasted eight hours too early. The simulation run with North American Model (NAM) forcing (300m_49_NAM) enabled the coarsest grid $(8.1 \mathrm{~km})$ to be eliminated because NAM forcing is at $12 \mathrm{~km}$ resolution as opposed to NARR forcing at $32 \mathrm{~km}$. The NAM simulation accurately captured the timing of the ramping event, although not its magnitude. Table 3.8 shows that a 1 $\mathrm{m} / \mathrm{s}$ improvement in error was achieved just by using different initialization and boundary conditions.

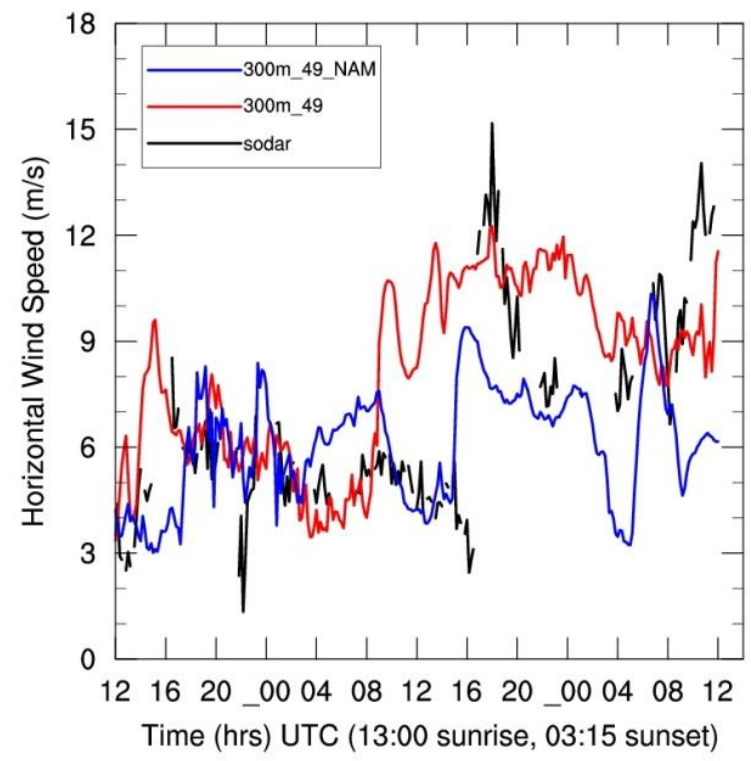

Figure 3.13: Time series of wind speed comparing NAM and NARR (base run) forcing during a locally-driven May ramping event. The NAM forcing correctly forecasts the timing of the ramping event although it under estimates its magnitude.

\begin{tabular}{|l|l|l|}
\hline & \multicolumn{2}{|l|}{$\begin{array}{l}\text { Locally-driven May } \\
\text { case }\end{array}$} \\
\hline Resolution & MAE & RMSE \\
\hline 300m_49 & 3.29 & 4.73 \\
\hline 300m_49_NAM & 2.38 & $\mathbf{3 . 0 6}$ \\
\hline
\end{tabular}

Table 3.8: Mean absolute error and root mean square error comparing NAM and NARR (base run) forcing during a locally-driven May ramping event. Lowest RMSE is in bold. 


\subsection{Conclusions}

This chapter presented simulation results using WRF-LES to capture synoptically- and locally-driven ramping events at a wind farm on the West Coast of North America. The wind ramping was closely represented with all grid resolutions and grid nesting configurations tested. These results seem counter-intuitive based on general practical recommendations to use higher resolution, but given the relatively simple terrain of this wind farm it is logical to conclude that resolution does not necessarily bestow the benefit of increased accuracy. Moreover, the LES turbulence closure did not show much benefit because it has difficulty at coarser resolutions with WRF. At very fine resolutions, the LES turbulence closures performed well, but there was little added benefit because at these resolutions, the domain is too small to show results differing too greatly from RANS (which provides the lateral boundary forcing). It is of interest to note that the synoptically-driven event was better simulated than the locally-driven event; this was expected because strong synoptic forcing usually overshadows other parameters. Land-surface parameters had more of an effect on the simulation results than resolution or our options for turbulence closure. Initialization conditions could also have a significant effect on simulation results in some cases. Future work will be performed on more complex terrain to investigate the effects of resolution and include additional experimentation with land-surface model parameters in WRF-LES, such as soil moisture and land-use, to determine how sensitive any of these changes may be. 


\section{Chapter 4: PF.WRF}

In this chapter, we use a fully-coupled subsurface-land-surface-atmospheric model to generate a wind energy forecast ensemble based on uncertainty in the characterization of subsurface hydraulic conductivity. Soil moisture has been shown to have a significant effect on local and mesoscale atmospheric processes, manifested in temperature, precipitation, and wind (e.g. Chen and Avissar, 1994). It has also been shown in work by Betts et al (1996), Beljaars et al (1996), Seuffert et al (2002) and Holt et al (2006), for example, that more advanced land surface formulations and soil moisture initialization in models generate more accurate forecasts. Traditionally, land surfaces and subsurfaces have been treated as simplified parameterizations in atmospheric forecast models (Golaz et al. 2001, Kumar et al. 2006). The forecasting system presented here replaces this parameterization with a 3-dimensional, dynamic, physical subsurface to generate more realistic soil moisture conditions. Soil moisture is both spatially heterogeneous over a wide range of scales (Famiglietti et al. 2008) and temporally variable (Wendroth et al. 1999, Western et al. 2004), and dependent, in part, on hydraulic conductivity. Hydraulic conductivity is spatially heterogeneous and can vary across several orders of magnitude over short distances; however, it has been shown to be spatially correlated, allowing hydraulic conductivity to be represented statistically as a correlated random field (Rubin 2003). Here, we run an ensemble forecast simulation based on different, but statistically equivalent, realizations of subsurface hydraulic conductivity stochastic fields. Using the results of these ensembles, we evaluate the circumstances under which hub-height wind speeds are affected by land surface-toatmosphere feedbacks, and when wind speeds are dominated by boundary forcing. 


\subsection{PF.WRF Simulations}

We examined high-resolution, wind forecast ensembles using the ParFlow-WRF (PF.WRF) model (Maxwell et al. 2010), a fully-coupled modeling system that incorporates the ParFlow hydrologic model (Ashby and Falgout 1996, Jones and Woodward 2001, Kollet and Maxwell 2006) into the Weather Research and Forecasting - Advanced Research WRF (WRFARW) model (Skamarock and Klemp 2008). Briefly, the models are coupled by replacing the simplified hydrology that is built into the WRF model with ParFlow, a variably-saturated surface and subsurface hydrologic model that solves the Richard's equation in three spatial dimensions for flow in the subsurface with integrated surface flow routing using the kinematic wave approximation. Mass and energy fluxes across the land surface are calculated using the Noah land surface model (Chen and Dudhia 2001).

\section{Model domain}

The coupled model domain comprised separate atmospheric and surface/subsurface domains. Because of fundamental differences in model physics and parameterizations between watershed models and atmospheric models, the two portions of the coupled domain were set up separately. Horizontal discretization was the same for both portions of the coupled domain. The horizontal grid was $14 \mathrm{~km}$ in the north-south direction and $10 \mathrm{~km}$ in the east-west direction with a horizontal resolution of $100 \mathrm{~m}$ in both directions. The atmospheric portion of the domain was vertically discretized in terms of 50 transient pressure levels defined fractionally from the land surface to the top of the domain at $20,000 \mathrm{~Pa}$, with a nominal vertical resolution of approximately $30 \mathrm{~m}$ near the land surface to $800 \mathrm{~m}$ near the upper boundary of the domain. Initial conditions and lateral boundary forcing were specified using NARR data, which was downscaled from the $32-\mathrm{km}$ resolution in the original data product to $100 \mathrm{~m}$. 
The subsurface portion of the domain used a vertical resolution of $0.5 \mathrm{~m}$, and extended from a depth of $20 \mathrm{~m}$ below mean sea level to the land surface. Neumann-type lateral and bottom boundary conditions and an overland flow top boundary condition were imposed to allow water to enter the system only via precipitation and to exit the system only by evapotranspiration or surface runoff. The digital elevation model of surface elevations was developed from the USGS National Elevation Dataset. USGS land-use data were also used to map cell-by-cell vegetation cover to the land surface. For the purposes of this simulation, soil cover was assumed to be 2 meters thick, making up the top 4 active grid cells of the model domain, overlying unconsolidated clastic alluvial sediments.

Literature values for the mean hydraulic properties of the three surface soil types mapped on the domain from USGS soil data, in addition to the alluvial sediments (Schaap and Leij 1998), are shown in Table 4.1. These values were used to construct statistical representations of the heterogeneous subsurface.

\begin{tabular}{ccccccc}
\hline & & \multicolumn{2}{c}{ Van Genuchten Parameters } & \multicolumn{2}{c}{ Hydraulic Conductivity } \\
\cline { 4 - 7 } Soil Type & Porosity & $\begin{array}{c}\text { Residual } \\
\text { Saturation }\end{array}$ & Alpha $\left(\mathbf{m}^{-1}\right)$ & $\mathbf{n}$ & $\mathbf{K}(\mathbf{m} / \mathbf{h r})$ & log (Std. Dev.) \\
\hline Sandy Loam & 0.387 & 0.101 & 2.692 & 1.445 & 0.016 & 0.660 \\
\hline Clay & 0.459 & 0.214 & 1.514 & 1.259 & 0.006 & 0.920 \\
\hline $\begin{array}{c}\text { Organic Material } \\
\text { (Silt Loam) }\end{array}$ & 0.439 & 0.148 & 0.501 & 1.660 & 0.030 & 0.740 \\
\hline Alluvium (Sand) & 0.375 & 0.141 & 3.548 & 3.162 & 0.269 & 0.590 \\
\hline
\end{tabular}

Table 4.1: Soil parameters from the literature used in the PF.WRF simulations.

The natural log transform of subsurface hydraulic conductivity is represented in this model as a correlated random field with specified mean, variance and correlation lengths. Hydraulic conductivity fields are generated using the Turning Bands random field algorithm 
(Tompson et al. 1989) following a correlation structure defined by the covariance,

$C(r)=\sigma_{\ln K}^{2} \exp \left(\frac{-r}{\lambda}\right)$

where $\sigma^{2}$ is variance, $r$ is the separation distance, and $\lambda$ is the correlation length. The random field generator is initialized with a random number seed. Changing the random number seed generates a different random field, while the global statistics remain constant. A separate stochastic hydraulic conductivity field was generated for each forecast ensemble member. An example of a stochastic hydraulic conductivity field is shown in Figure 4.1.

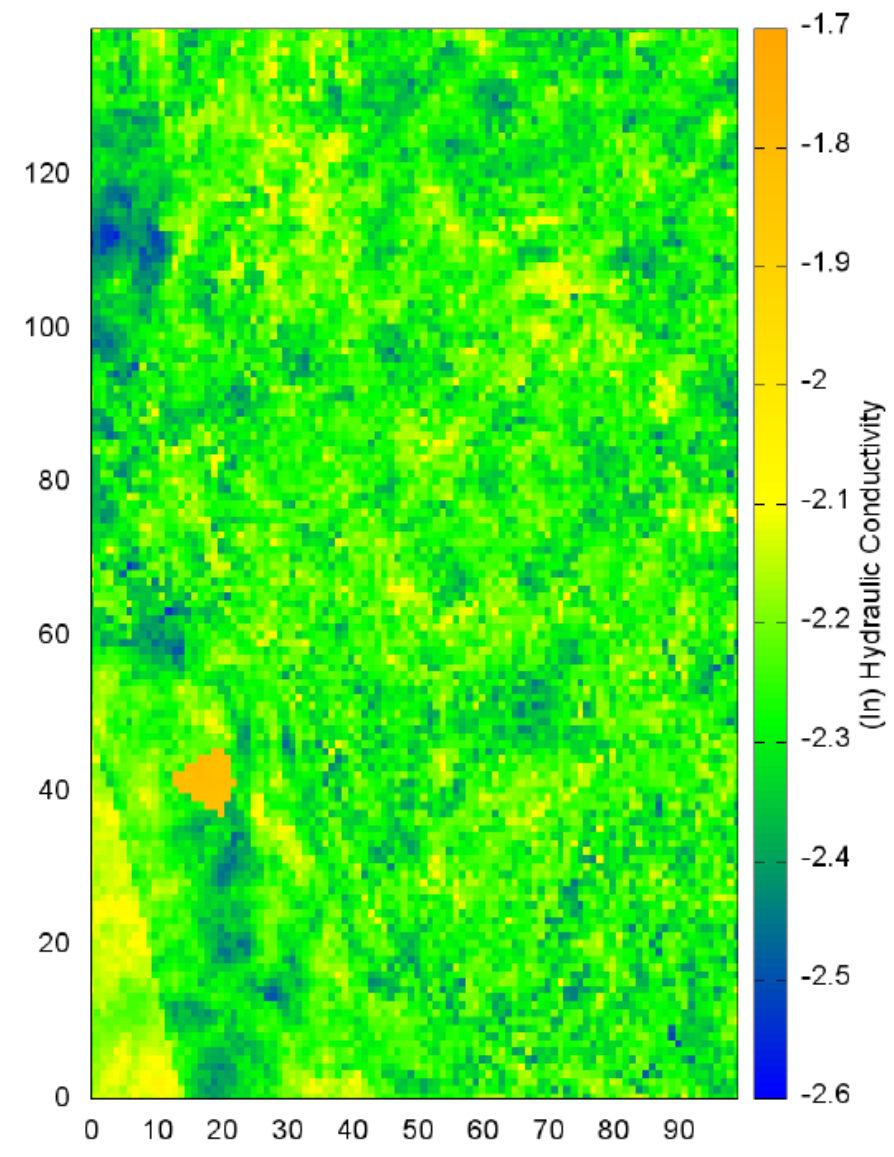

Figure 4.1: The ensemble averaged stochastic field of hydraulic conductivity used in the PF.WRF simulations shows spatial heterogeneity across the wind farm. 


\section{Soil moisture initialization}

The spin-up phase, a critical component in the use of a forecast model, was completed to generate realistic soil moisture conditions with which to initialize the subsurface portion of the fully-coupled PF.WRF model. We used ParFlow coupled to the Common Land Model (CLM, Dai et al. 2003) to simulate hourly soil moisture fields over a two year period for each ensemble member. Meteorological reanalysis data from the North American Land Data Assimilation System (NLDAS, Mitchell et al. 2004) was used for atmospheric forcing for the spin-up runs. While the time period employed in this spin-up may not be sufficient for deep groundwater to reach an equilibrium state, it is expected that soil moisture at and near the surface equilibrates and perched water-bearing zones begin to form within one rainy season in this location. Since the forecast model system focuses on land surface-to-atmosphere feedbacks and their effects on wind speed, moisture at and near the surface is considered critical.

\section{Forecast ensembles}

We completed forecast ensemble simulations for three wind ramping events: the Case $\mathrm{L}$ event in July, the Case S event in February, and the May local-forcing event. We examined a 40-hour time period encompassing the wind ramp for each event. Each ensemble was allowed to run for 24 hours (simulated time) to spin-up before the beginning of the observation periods. The forecast model ensembles each comprise 11 ensemble members. Atmospheric initial conditions and boundary forcing were identical for each ensemble member. The ensemble members differed only in their hydraulic conductivity fields and their soil moisture initializations, which are directly correlated to hydraulic conductivity. The hydraulic conductivity fields used for the forecast ensemble runs were the same fields used in the corresponding spin-up simulations, as described above. 


\subsection{Results and Discussion}

For each wind ramping event, we examined a 40-hour time period that included both low wind speeds prior to the ramp and the ramp itself in order to explore the capabilities of the fullycoupled hydrologic and atmospheric model before and during a wind ramp event. Our analysis of the model results is based on two-dimensional time slices taken at peak wind speed during each ramp event, time series of domain averaged variables, and time series of variables at points with available wind speed observations. We observed variables as they relate serially from the subsurface into the atmosphere beginning with saturation (soil moisture), which is a function of hydraulic conductivity among other variables. The latent heat flux represents evapotranspiration (ET) expressed in terms of energy, which embodies the interaction of energy and moisture fluxes between the land surface and the atmosphere. We evaluated the effects of land surface-toatmosphere feedbacks on wind speed magnitude at hub-height ( 80 meters above ground level). In addition to analyzing the magnitudes of these variables, we also examined the relationships between their variances in order to evaluate the impact of the land surface on wind speed observations versus prevailing winds provided by the model boundary forcing data.

\section{Synoptically-driven ramping event (February)}

The observed ramping event for the Case S occurred at approximately 18:00 UTC (10:00 PST), 25 hours into the period, while the simulated ramping event was forecasted to occur 5 hours earlier, or 20 hours into the period. This is the only ramping event to fall within two weeks following a rain event. Because this ramping event took place during the wet season and followed significant rainfall, simulated saturation at the surface, as shown in the time slice in Figure 4.2a, was the highest of the three ramping events. The saturation in the southwest portion of the domain was high, making ET (or latent heat flux) in this area energy-limited. The 
remainder of the domain was water-limited. Small scale spatial variability in saturation was reproduced in the latent heat flux field, as shown in Figure 4.2b. Latent heat flux also displayed a larger scale spatial pattern that resembled the pattern of variability seen in hub-height wind speed (Figure 4.2c), and is a bridge between variability in the atmosphere and the land surface.
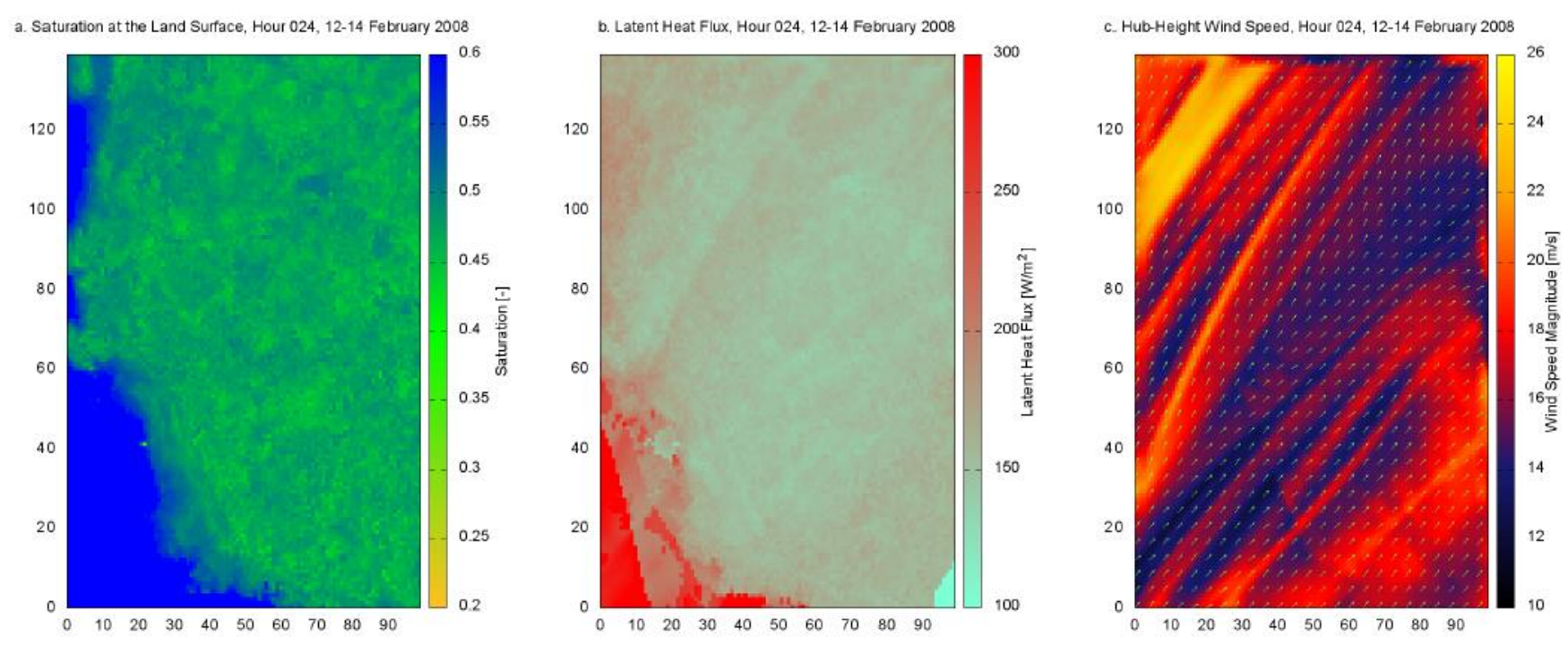

Figure 4.2: Ensemble average time slices during the February Case $\mathrm{S}$ ramp event show simulated (a) saturation conditions at the land surface, (b) latent heat flux, and (c) hub-height wind speed across the wind farm domain.

Saturation at the surface did not change substantially during the forecasted 40-hour time period while latent heat flux showed the expected diurnal cycle (Figure 4.3). The ensemble variance in latent heat flux also followed this diurnal cycle. When latent heat flux approached zero during the nighttime hours, as is realistically expected, it did so for all ensemble members, and the variance dropped to near zero. 


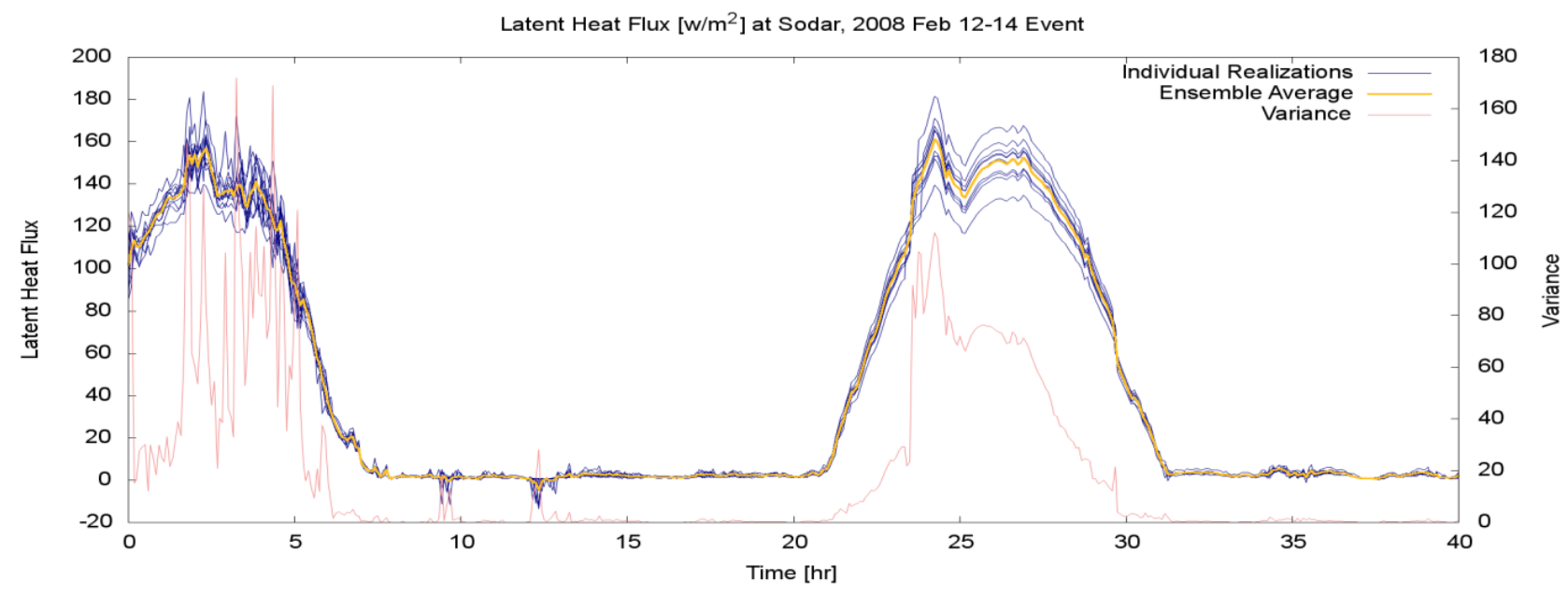

Figure 4.3: Time series of latent heat flux at the SODAR location for the February Case $S$ ramping event shows a realistic diurnal cycle with peak evapotranspiration during the afternoon hours and near zero evapotranspiration at night.

An important relationship occurs between the variances of latent heat flux and hub-height wind speed, shown for three observation locations in Figure 4.4. The simulated wind speeds, shown as a dotted line through each panel of Figure 4.4, increased at each location starting at hour 20, and recovered after hour 30. During this time, the variance in hub-height air temperature and hub-height wind speed dropped to near zero, indicating that each ensemble member reached the same solution for the wind and temperature fields. This is an indication that the elevated wind speeds of the ramping event were decoupled from local land-atmosphere interactions, and were dominated by boundary forcing. The variance in latent heat flux followed a diurnal pattern independent of the wind speed; however, in the domain averaged time series, the daytime ensemble variance was dampened during the ramping event as compared to the variance during the previous day. The higher variances in hub-height temperature and wind speed when the wind speed was lower indicate that the effects of land surface feedbacks with the atmosphere may be more localized during calm wind periods. 


\section{Comparison to February observations}

Simulated hub-height wind speeds for Case S were compared to observed wind speed data from two meteorological towers and the SODAR. Measurements were collected at $80 \mathrm{~m}$ above ground level at one met tower. The other met tower provided wind speeds at 50 meters above ground level. Time series plots of the observed hub-height wind speeds overlain on the simulated hub-height wind speeds for each of the three points are shown in Figure 4.5. The simulated values closely approximated the magnitude of the observed hub-height wind speeds in the Case $S$ event with hub-height wind speeds of 15 to $20 \mathrm{~m} / \mathrm{s}$; however, the simulated ramp event started ahead of the observed event, and was of shorter duration. As noted above, the nearzero ensemble variance in wind speeds during the ramping event indicated that the simulated winds were driven by boundary forcing, so the timing and duration of the simulated wind conditions were primarily an expression of large-scale flow patterns that were not resolved inside the small scale domain used in this simulation. 
a.

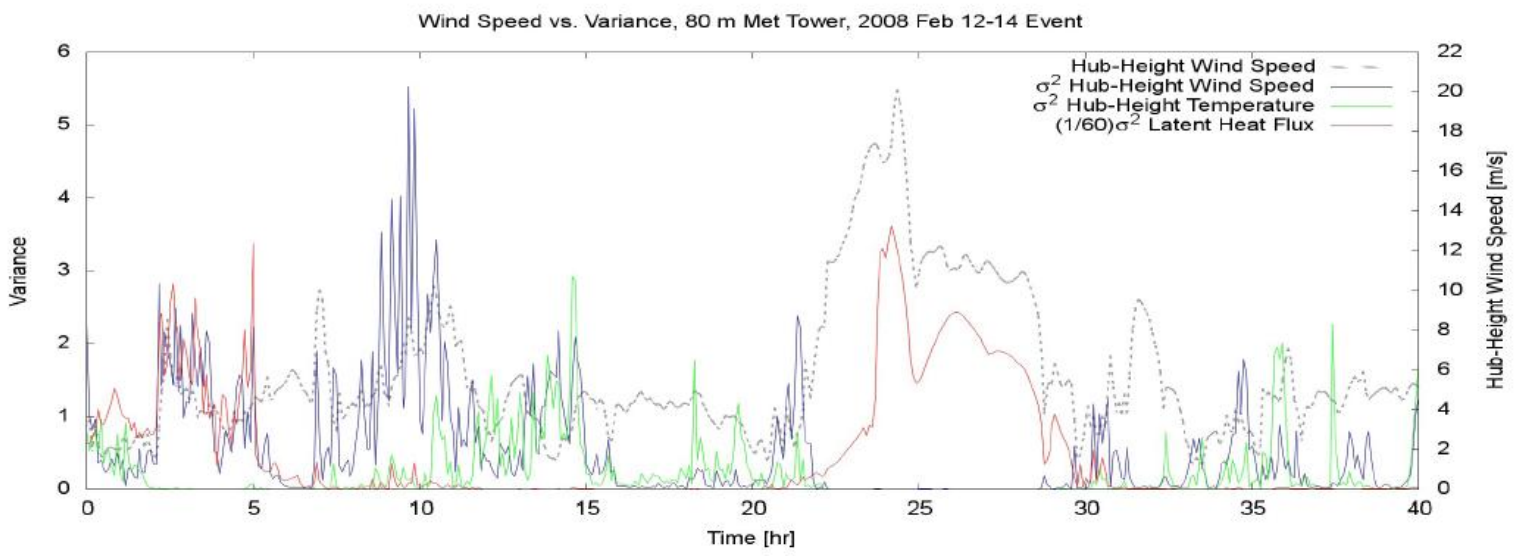

b.

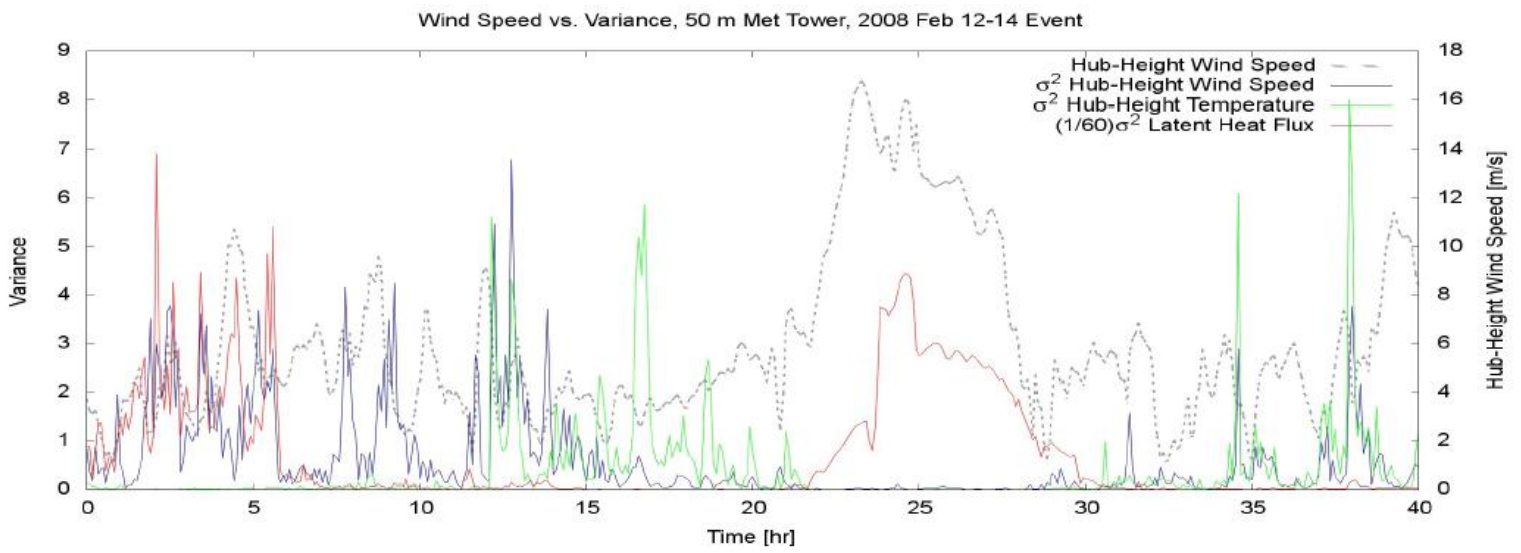

C.



Figure 4.4: Time series comparison of variances of simulated latent heat flux, hub-height air temperature, and hub-height wind speed for the February Case $S$ ramping event at the (a) 80 $\mathrm{m}$ meteorological tower, (b) $50 \mathrm{~m}$ meteorological tower, and (c) SODAR locations. 
a.

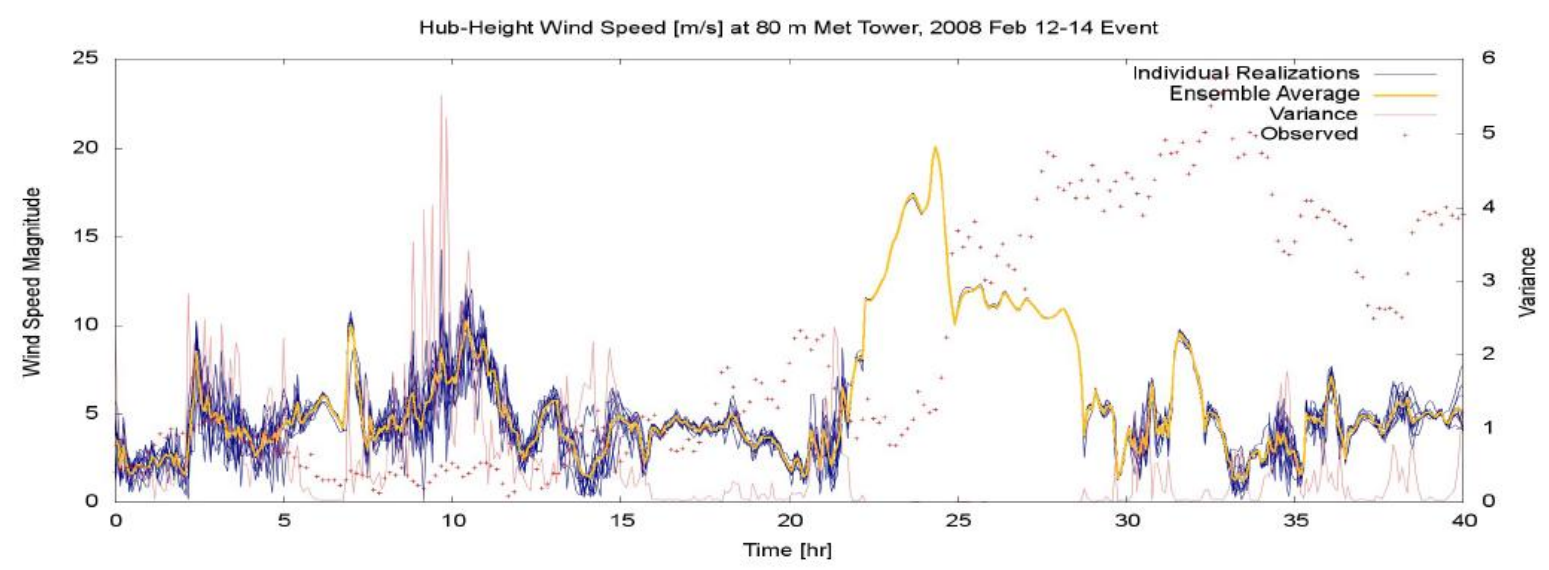

b.

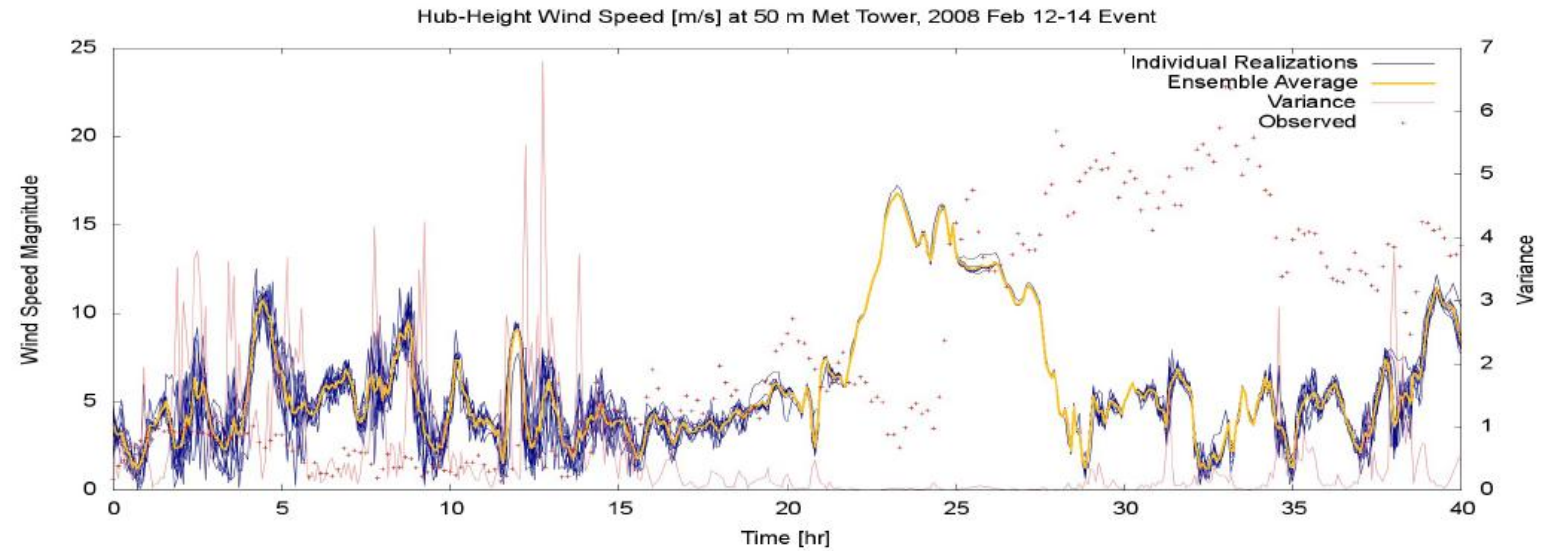

c.

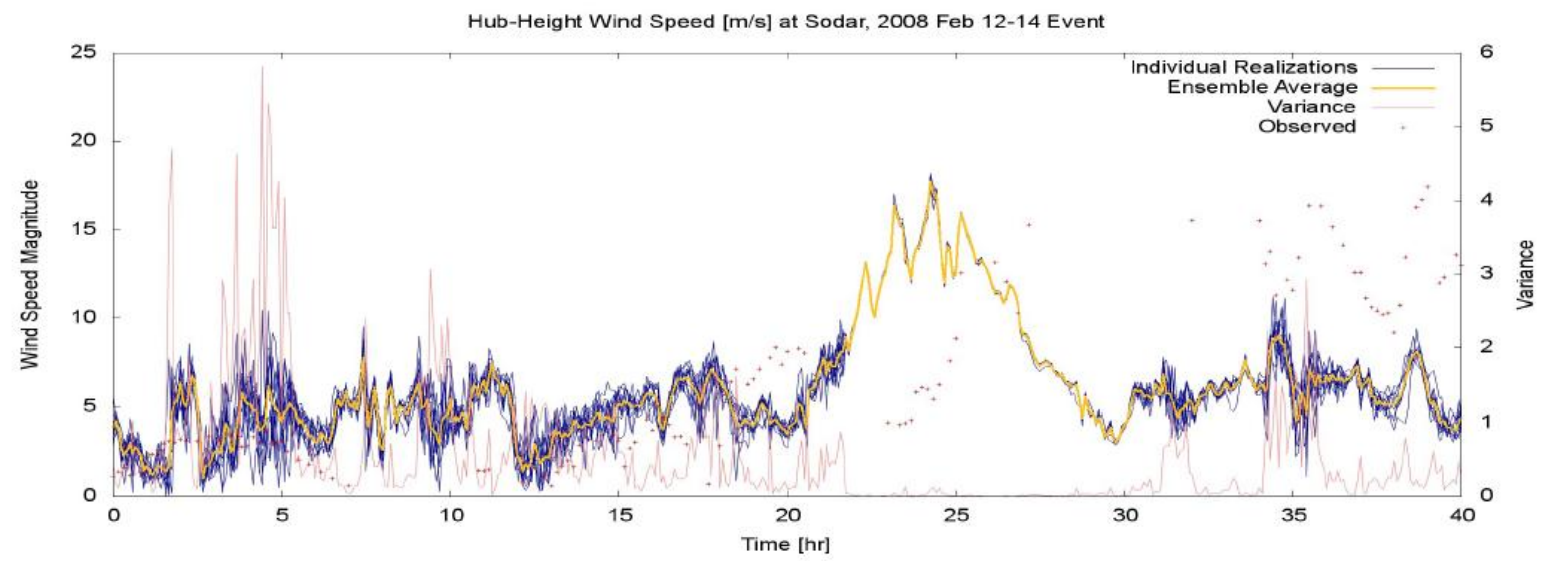

Figure 4.5: Time series of observed hub-height wind speeds for the February Case S ramping event at the (a) $80 \mathrm{~m}$ meteorological tower, (b) $50 \mathrm{~m}$ meteorological tower, and (c) SODAR, in comparison to the model ensembles. 
Locally-driven ramping event (May)

The peak observed wind for the May ramping event occurred at approximately 18:00 UTC (10:00 PST), 29 hours after the start of the run. The peak simulated wind occurred at 07:00 UTC, 19 hours after the start of the model run, and 10 hours earlier than observed. A rain gauge near the site recorded no substantial rainfall within the forty-five days preceding the ramping event. Therefore the soil moisture, shown in Figure 4.6a, was lower in the portion of the domain that tends to be water-limited as compared with the winter Case S event. The simulated ramping event occurred during the night, so there was minimal latent heat flux at this time. Measurable latent heat flux was recorded in the model output only in the highly saturated southwest corner of the domain, as shown in Figure 4.6b. The spatial patters which appeared to propagate between coupled fields in the Case S ramping event were not seen in the May locally-driven ramping event due to dry soil moisture conditions. Also, the spatial pattern of wind speeds (Figure 4.6c) was not similar to patterns in latent heat flux.
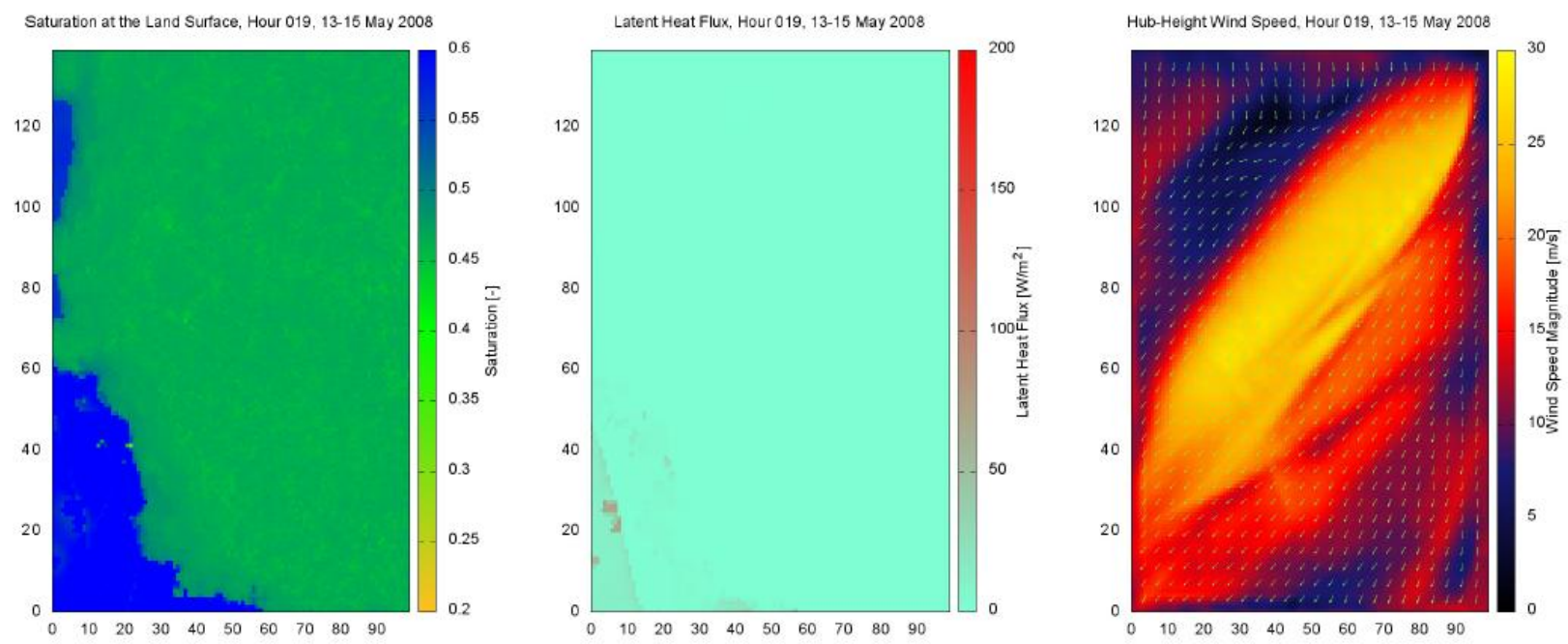

Figure 4.6: Ensemble average time slices during the locally-driven May ramping event show simulated (a) saturation conditions at the land surface, (b) latent heat flux, and (c) hub-height wind speed across the wind farm domain. 


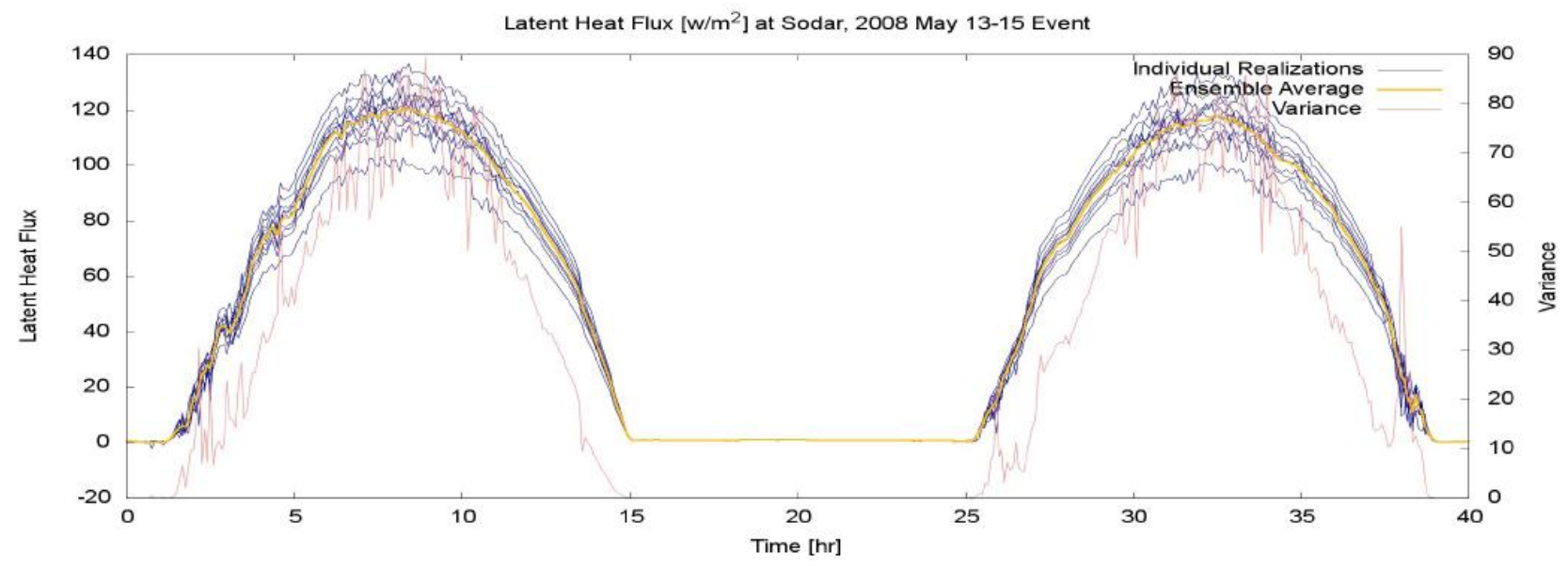

Figure 4.7: Time series of simulated latent heat flux at the location of the SODAR for the locally-driven May ramping event shows a realistic diurnal cycle.

Similar to the synoptically-driven ramping event, saturation at the surface showed little change throughout the observation period for the May ramping event. Latent heat flux, shown in Figure 4.7, displayed the expected diurnal cycle. The variance in latent heat showed the same diurnal cycle and dropped to near zero during night time hours. Similar to Case S, the ensemble variances in wind speed and temperature (shown for two observation locations in Figure 4.8) were small as the wind speed increased. However, there was a spike in both of these variances at hour 19 (07:00 UTC) which corresponded to the peak in simulated wind speed. This spike in the variances may indicate that the simulated winds were enhanced by land surface processes which require further investigation. 
a.

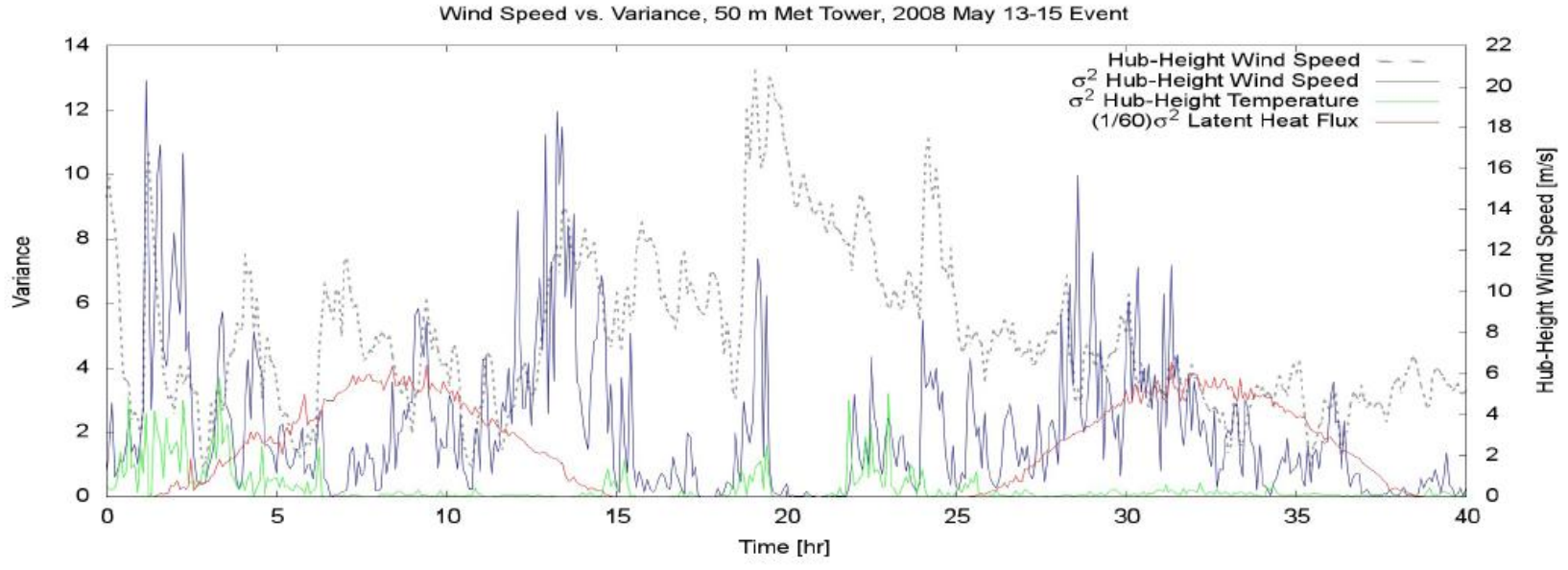

b.



Figure 4.8: Comparison of simulated variances of latent heat flux, hub-height air temperature, and hub-height wind speed for the locally-driven May ramping event at the (a) $50 \mathrm{~m}$ meteorological tower, and (b) SODAR locations.

\section{Comparison to May observations}

Simulated hub-height wind speeds were compared with observed wind speed data collected at 50 meters above ground level from the meteorological tower and SODAR wind speed data collected at $80 \mathrm{~m}$ above ground level. Figure 4.9 shows time series plots of observed hub-height wind speeds overlain on simulated hub-height wind speeds for each of the two 
observed locations. The simulated wind ramp occurred 10 hours earlier than the observed event with simulated speeds of 20 to $25 \mathrm{~m} / \mathrm{s}$. The low variance in hub-height temperature and wind speed during the simulated ramping event suggests that, as with the Case S ramping event, these atmospheric variables were controlled primarily by the boundary forcing, and an error in the timing in the boundary conditions propagated directly to the results of this forecast. The spike in ensemble variance in hub-height wind speed at the peak of the simulated ramping event suggested an effect from land surface to atmosphere feedbacks that could be amplified by latent heat flux if the simulated ramping event were to take place during the daytime hours. 
a.

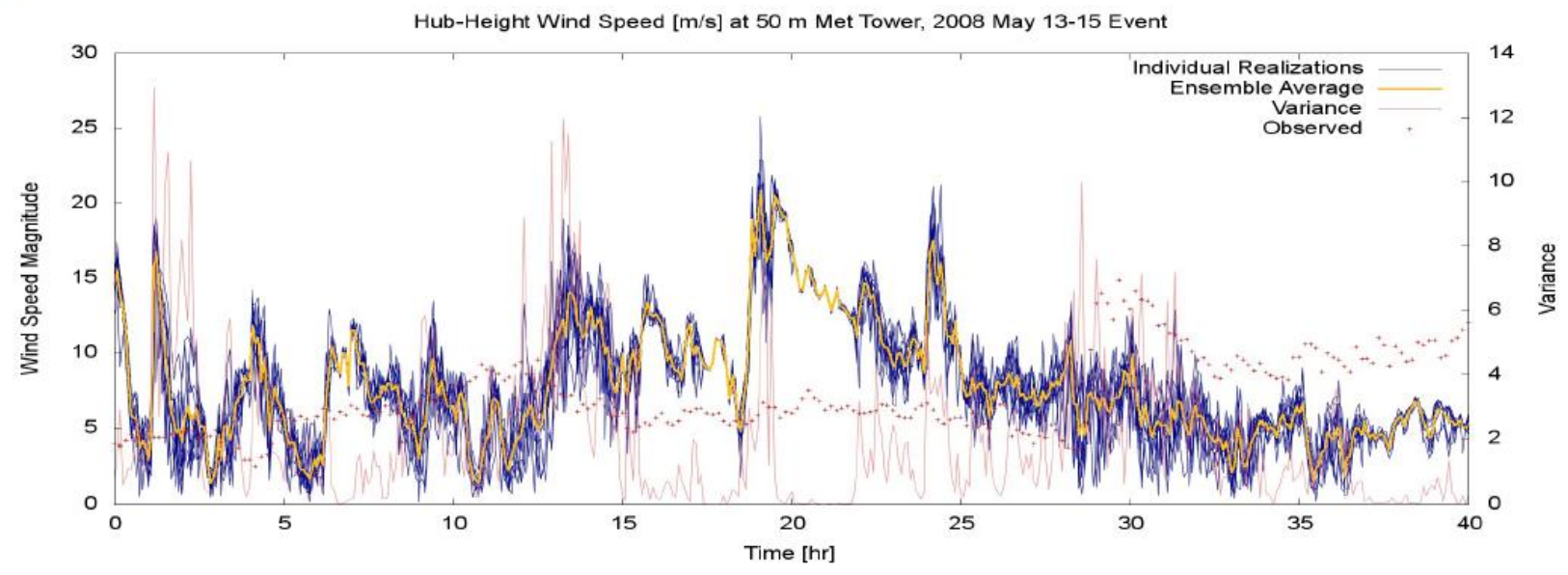

b.



Figure 4.9: Time series of hub-height wind speeds for the locally-driven, May ramping event at the (a) $50 \mathrm{~m}$ meteorological tower and (b) SODAR as compared to the forecast runs.

\section{Locally-driven ramping event (July)}

The peak observed wind speed for the Case L ramping event occurred at approximately 8:00 UTC (24:00 PST), 35 hours into the observation period. The peak simulated wind speed occurred at 17:00 UTC, 17 hours into the observation period. Unlike the Case S and May ramping events, hub-height wind speed increased gradually over an 8 hour period. The Case L ramping event occurred in mid-summer and the most recent rainfall was more than 70 days 
earlier. Saturation at the surface, shown in Figure 4.10a, was low, over most of the domain. Significant latent heat flux, shown in Figure 4.10b, was only present in the southwest corner of the domain where a shallow water table maintained soil moisture during the dry season. The spatial pattern of latent heat flux closely matched that of saturation at the surface; however, the spatial distribution of hub-height wind speeds (Figure 4.10c) appeared to be independent of the land-surface moisture variables.
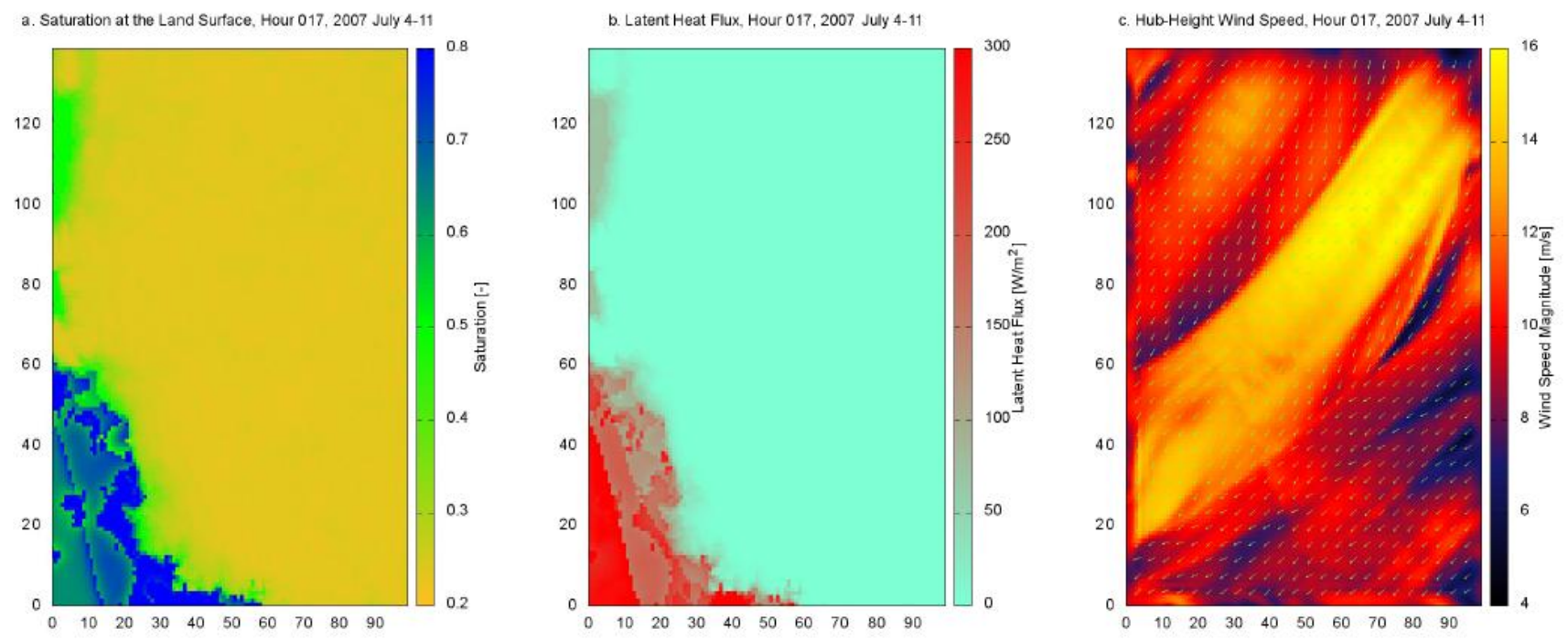

Figure 4.10: Ensemble average time slices during the Case $L$ ramping event show simulations of (a) saturation conditions at the land surface, (b) latent heat flux, and (c) hub-height wind speed across the wind farm.

The absence of precipitation in the water-limited area kept surface saturation constant and low through the model run. Thusly, domain-averaged latent heat flux (Figure 4.11) was low in the wind farm domain, and showed the expected diurnal cycle. Contributions to domain averaged latent heat flux came from the southwest corner of the domain. The relationship between the ensemble variances for latent heat flux and that for hub-height wind speed differed for the Case $\mathrm{L}$ ramping event because of the absence of significant latent heat flux over most of 
the domain. Figure 4.12 is a plot of these ensemble variances with hub-height wind speed in the background. The variance in latent heat flux was close to zero for the entire observation period. When the simulated hub-height wind speed began to increase at hour 14 , the variance of the wind speed decreased sharply, which indicated that, like the Case S and May ramping events, the simulated wind increase was controlled by the boundary forcing. However, the ensemble variance in wind speed increased immediately following the peak hub-height wind speed at hour 17. Since the differences between ensemble members were the hydraulic conductivity fields and soil moisture initializations, any variation in wind speeds between ensemble members resulted from interactions between the land surface and the atmosphere. It is possible that latent heat flux in the southwestern portion of the domain affected wind speeds elsewhere in the domain. It is also possible that sensible heat flux (not shown) was a significant factor.

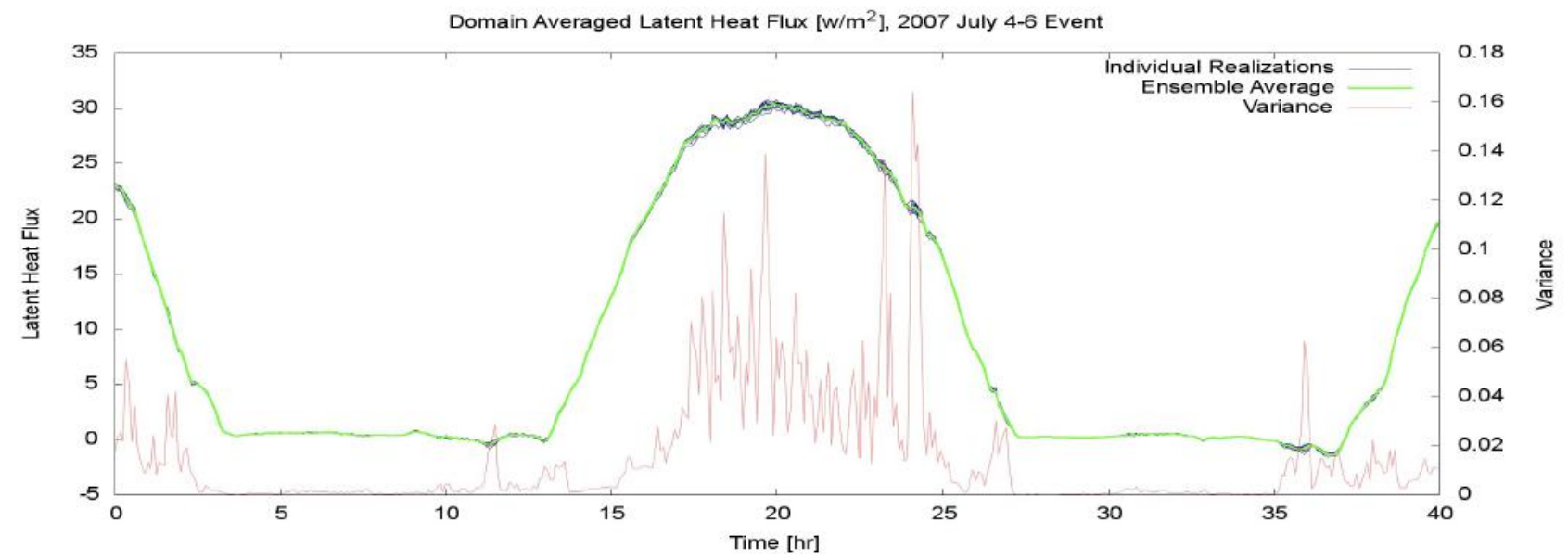

Figure 4.11: Time series of domain averaged latent heat flux for the Case $L$ ramping event shows a realistic diurnal cycle and low peak values of evapotranspiration because of dry soil conditions. 


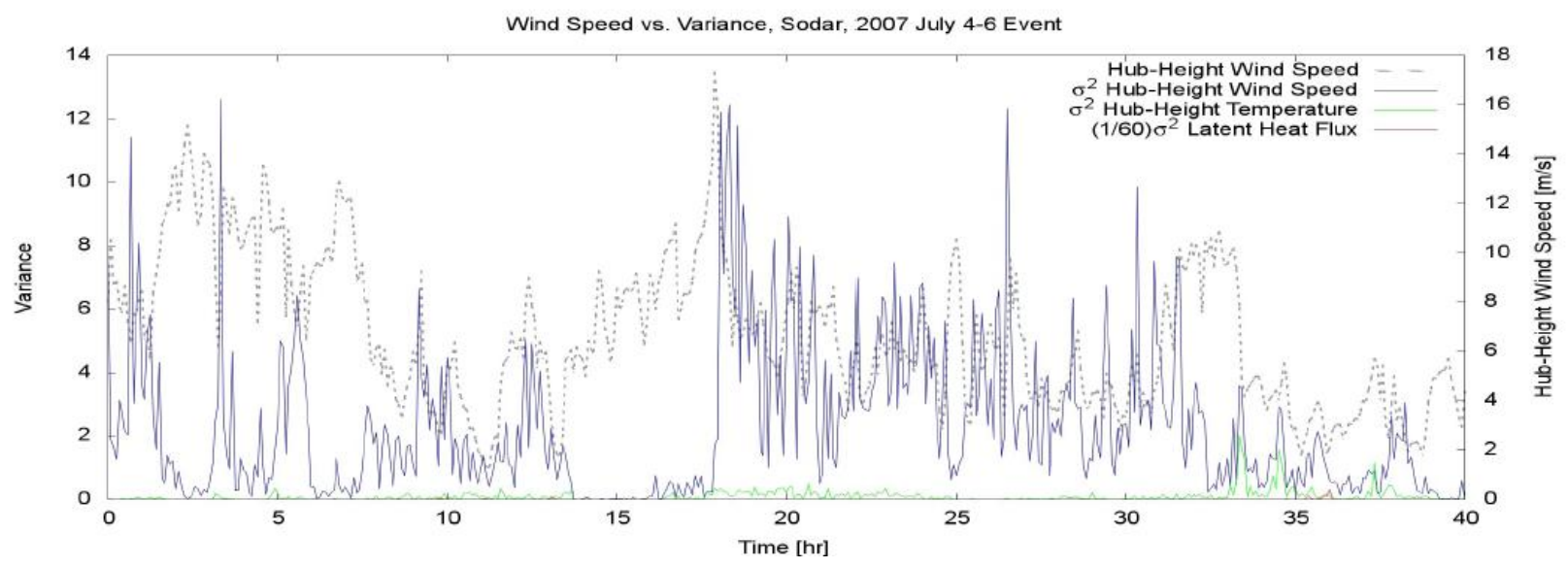

Figure 4.12: Time series of variances of simulated latent heat flux, hub-height air temperature, and hub-height wind speed for the Case $L$ ramping event at the SODAR location.

\section{Comparison to July observations}

Simulated hub-height wind speeds were compared to observations collected from the SODAR at $80 \mathrm{~m}$ above ground level. A time series plot of observed wind speeds overlain on simulated wind speeds is shown in Figure 4.13. The simulated hub-height wind speed values were a good approximation of the magnitude of the observed wind speeds at 15 to $20 \mathrm{~m} / \mathrm{s}$; however, the simulated ramping event was approximately 17 hours ahead of the observed event. As noted in the discussions for the Case $\mathrm{S}$ and May ramping events, the boundary forcing appeared to exert significant control over hub-height wind speeds, particularly with the faster winds associated with the ramping events. There was higher variance in the lower wind speeds which occurred primarily during the daylight hours and suggests the importance of feedbacks between the land surface and the atmosphere. 


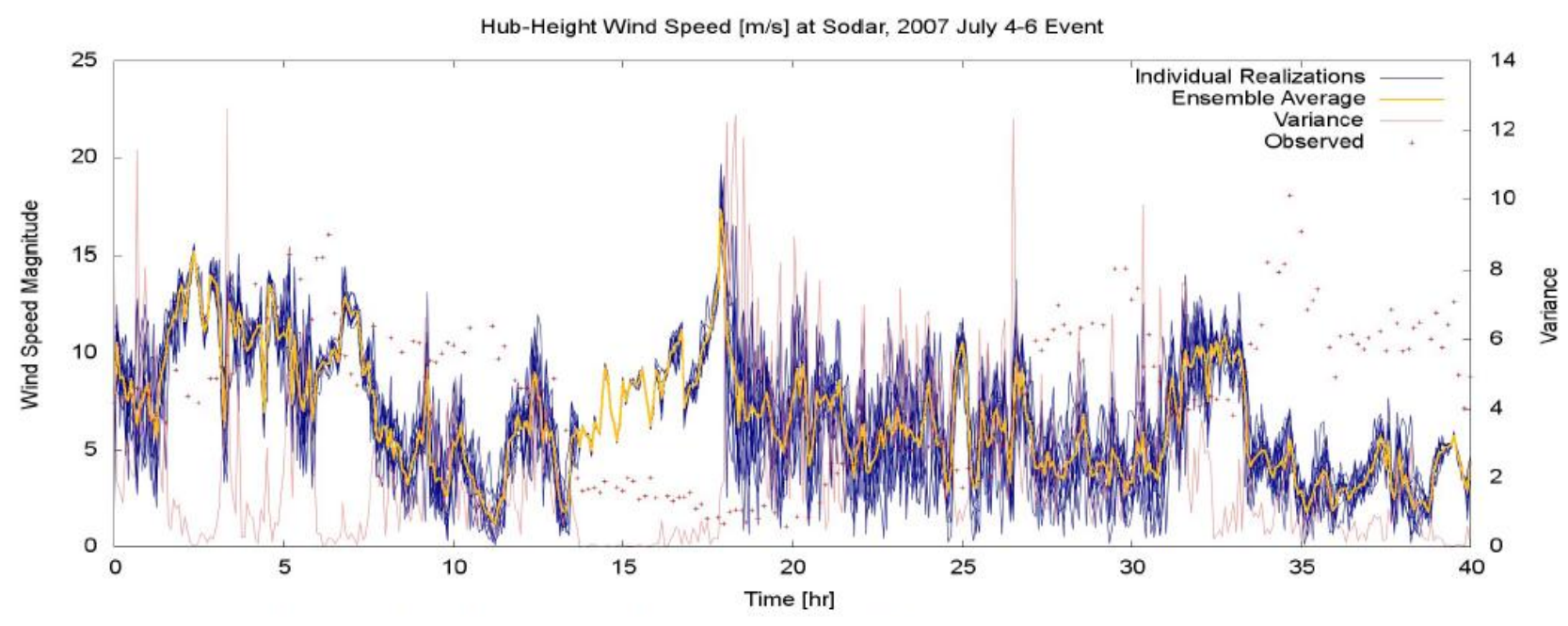

Figure 4.13: Time series of hub-height wind speed for the Case $L$ ramping event comparing the forecasted wind speeds to SODAR observations.

\subsection{Conclusions}

Based on the results of this study, we make the following conclusions regarding the wind forecast model ensembles run with PF.WRF. The wind ramps at this location were likely strongly influenced by external forcing. The influence of land surface-to-atmosphere feedbacks were mostly observed in the model at low wind speeds while boundary forcing appeared to control the higher wind speeds. This makes sense because higher wind speeds generally occurred at night at this wind farm, a period when boundary forcing would be significant, and lower wind speeds generally occurred during the daylight hours, a period when exchanges of moisture and energy between the surface and atmosphere would be important forcing mechanisms. PF.WRF appeared to capture the magnitude of the wind speeds associated with the ramping events with reasonable accuracy, while the timing of the wind ramping events appeared to be controlled by the forcing data. Errors in timing in the forcing data were likely carried into the model output and the ramping events were predicted too early. As shown by Williams and 
Maxwell (2011), assimilating observed hydraulic conductivity data may improve the forecasts further by reducing uncertainty in subsurface characterization and in variables that depend directly or indirectly on hydraulic conductivity. Thus, the spatial and temporal accuracy of our ramping forecasts could be improved by expanding the domain to capture the non-localized effects of soil moisture heterogeneity. 


\section{Chapter 5: Model intercomparison and recommendations to the wind industry}

\section{Overview}

Most operational wind energy forecasting systems use refined resolution of the lower layers of the atmosphere (Lundquist 2008, Porter and Rogers 2010) to capture shallow surfacebased phenomena poorly represented in "out-of-the-box" mesoscale simulations. This led us to investigate whether research-grade forecasting models, including a higher-resolution model, WRF-LES, and a coupled subsurface-surface-atmosphere model, PF.WRF, as well as skilled expertise using mesoscale WRF, could significantly improve wind power forecasts, and specifically, for forecasting ramping events. The results of this study show that improved forecasting of all ramping events, both synoptically-driven and locally-driven, was obtained by running mesoscale WRF with user-defined, site-specific choices for horizontal resolution, vertical spacing, nesting levels, and surface conditions. This determination is based on relatively low root mean square errors between forecasted wind speeds from the "skilled" version of WRF and observed wind speeds from the SODAR. Although the LES closure schemes performed well, they did not add any additional benefit to reducing the forecasting error. The RMSE values in Table 5.1 indicate the modeling error $(\mathrm{m} / \mathrm{s})$ associated with forecasting the $0-200 \mathrm{~m}$ above ground level wind speeds during each ramping event for the "out-of the-box" version of mesoscale WRF, "skilled" version of mesoscale WRF, WRF-LES, and PF.WRF. 


\begin{tabular}{|c|c|c|c|c|}
\hline & \multicolumn{2}{|c|}{ Case S (Feb.) } & \multicolumn{2}{|c|}{ Case L (July) } \\
\hline RMSE (m/s) & average & range & average & range \\
\hline \multicolumn{5}{|c|}{ unskilled "out-of-the-box" mesoscale WRF } \\
\hline \multicolumn{5}{|c|}{ Different horizontal resolutions } \\
\hline $900 \mathrm{~m}$ & 4.74 & $4.27-5.21$ & -- & -- \\
\hline $2700 \mathrm{~m}$ & 4.92 & 4.92 & -- & -- \\
\hline $8100 \mathrm{~m}$ & 2.99 & $2.93-3.04$ & -- & -- \\
\hline \multicolumn{5}{|l|}{ skilled mesoscale WRF } \\
\hline \multicolumn{5}{|c|}{ Different horizontal resolutions } \\
\hline $300 \mathrm{~m}$ & 2.30 & & 2.54 & \\
\hline $900 \mathrm{~m}$ & 2.23 & & 2.48 & \\
\hline $2700 \mathrm{~m}$ & 2.16 & & 2.47 & \\
\hline $8100 \mathrm{~m}$ & 2.30 & & 2.69 & \\
\hline \multicolumn{5}{|c|}{ Different vertical spacing } \\
\hline 40 (standard WRF) & 2.39 & & 2.59 & \\
\hline 49 (tanh spaced) & 2.30 & & 2.54 & \\
\hline $\begin{array}{l}70(10 \mathrm{~m} \text { spacing in the } \\
\text { lowest } 200 \mathrm{~m} \text { ) }\end{array}$ & 2.33 & & 2.55 & \\
\hline \multicolumn{5}{|c|}{ WRF-LES with 1.5 TKE closure } \\
\hline \multicolumn{5}{|c|}{ Different horizontal resolutions } \\
\hline $100 \mathrm{~m}$ & 2.43 & & 2.56 & \\
\hline $300 \mathrm{~m}$ & 3.14 & & 4.09 & \\
\hline $900 \mathrm{~m}$ & 5.51 & & -- & \\
\hline \multicolumn{5}{|l|}{ PF.WRF } \\
\hline ensemble average* & 5.55 & $5.29-5.81$ & 4.52 & $4.00-5.03$ \\
\hline
\end{tabular}

Table 5.1: Average and range of root mean square errors $(\mathrm{m} / \mathrm{s})$ for the configurations used in each of the three models for Case $S$ and Case $L$ ramping events. Highest agreement (i.e., lowest RMSE) between the forecast simulations of 0-200 AGL wind speed and observations of 0-200m AGL wind speed is highlighted in bold. * Note that the PF.WRF RMSE values are relatively high; this is likely due to the incorrect timing of the forecasted ramp events.

A more detailed discussion of the models' ability to forecast the ramping events is as follows: 


\section{Mesoscale WRF}

We found poor agreement between the simulated wind conditions and SODAR observations using the "out-of-the-box" version of mesoscale WRF. It is clear that the performance of mesoscale WRF shown here is suboptimal; the timing of the ramp was incorrectly forecast by several hours by simulations with either the MYJ or YSU PBL scheme. Furthermore, increasing the horizontal resolution to the limit of the terrain resolution $(1 \mathrm{~km})$ did not universally improve the forecast. Instead, the YSU PBL scheme showed a slight advantage in predicting total wind speed during the ramping event, while MYJ showed better agreement for capturing the shift in wind direction. While it appears that the finer resolution model runs are useful for capturing changes in wind direction, better agreement was found at coarser resolutions when modeling abrupt changes in wind speed. The failure of "out-of-the-box" WRF to capture not only the timing of a ramping event but the shape of the wind profile during the ramping event indicates that the set-up and execution of such simulations for wind power forecasting requires skill and tuning of the simulations for a specific wind farm.

\section{WRF-LES}

WRF was run at various horizontal and vertical resolutions and nesting levels to test "skilled" simulations of mesoscale WRF and with different closure schemes to test the advantages of using a more sophisticated (and more computationally-expensive) forecast model, WRF-LES, to simulate wind power ramping events. The observed ramping events were closely represented with all grid resolutions and grid nesting configurations tested, and "skilled" WRF runs showed substantial improvement over the "out-of-the-box" WRF simulations (see improved 
RMSE values in Table 5.1). Interestingly, little improvement was found when using the highest vertical and horizontal resolutions for both the 48-hour and week-long simulations. The weeklong simulations showed small, but insignificant improvement in the distribution of wind speed and turbulence intensity where the finer resolutions were used. These results seem counterintuitive based on general practical recommendations to use higher resolution, but given the relatively simple terrain of this wind farm it is logical to conclude that resolution does not necessarily bestow the benefit of increased accuracy. These results suggest that all of the model grids, even as course as $2.7 \mathrm{~km}$, are adequate to use at a relatively simple topography wind farm, including this one that had elevation gains of less than $120 \mathrm{~m}$. 2-way nesting did not significantly improve the forecasts compared to 1-way nesting. At very fine resolutions, the LES turbulence closures performed well, but there was little added benefit because at these resolutions, the domain is too small to show results differing too greatly from RANS (which provides the lateral boundary forcing).

It is of interest that the synoptically-driven February event was better simulated than the locally-driven events; this was expected because strong synoptic forcing usually overshadows other parameters. The simulations of wind speed were more sensitive to changing the landsurface parameters than the choice of horizontal or vertical resolution, nesting, or closure scheme.

\section{PF.WRF}

Based on the results of this study, we make the following conclusions regarding the wind forecast model ensembles we completed using PF.WRF. Wind ramps of this magnitude and 
at the location of this wind farm appear to be strongly influenced by external forcing as the improved subsurface-surface-atmosphere coupling of the hydrologic properties did not significantly improve the forecasts, as compared to mesoscale WRF and WRF-LES.

PF.WRF appears to capture the magnitude of the wind speeds associated with the ramping events with reasonable accuracy but had significantly higher root mean square errors than the "skilled" runs of WRF or WRF-LES and had difficulty with predicting the timing of the ramping events. The influence of strong land surface-to-atmosphere feedbacks was mostly observed in the model at low wind speeds, during non-ramping periods, and corresponded with daylight hours when exchanges of energy and moisture are significant. The magnitude and timing of peak wind speeds during the ramping events appeared to be controlled by boundary forcing in the model. As such, errors in timing in the forcing data were likely carried into the model output and caused a mismatch between the occurrences of observed peak wind speed and forecasted peak wind speed.

\section{Recommendations and future work}

While our findings are based on a few case studies and longer simulation runs would reveal additional insight into the model specifications needed for accurate ramp forecasting, our results suggest that the "out-of-the-box" mesoscale version of WRF is likely inadequate for ramp forecasting at most multi-megawatt wind farms; this deficiency will only increase for forecasts for wind farms in complex terrain. Future work is needed to investigate the effects of higher resolution on forecasts for wind farms in complex terrain as the wind farm in this study is located in relatively simple topography. Our results suggest that future wind forecasting models of ramping events require "skilled" user expertise and should exploit recent 
developments in refined simulations including large-eddy simulation (see Mirocha et al. 2011 and Liu et al. 2011). The site location and seasonal timing of ramping events studied here might not have also fully showed the utility of a coupled subsurface-surface-atmosphere model. Either, soil conditions were too dry during the ramping events (except for the February case) to show PF.WRF's full utility in parameterizing surface energy and moisture exchange, or the groundwater influence on surface moisture is not significant at this site as it is in other locations. Further utility of PF.WRF could be tested by expanding the model domain to capture the nonlocalized effects of soil moisture heterogeneity. 


\section{Chapter 6: Acknowledgements and References}

\section{Acknowledgements}

The authors express great appreciation to Iberdrola Renewables, Inc. for the collection and provision of the observational data, and in particular, thank Dr. Justin Sharp, Dr. Mike Zulauf, and Jerry Crescenti. This work was funded by the Department of Energy's Wind and Water Power Program Office under the Renewable Systems Interconnect Support program (BNR Code EB2502010). LLNL is operated by Lawrence Livermore National Security, LLC, for the

DOE, National Nuclear Security Administration under Contract DE-AC52-07NA27344.

\section{References}

Antoniou I., S.M. Pedersen, and P.B. Enevoldsen (2009) Wind shear and uncertainties in power curve measurement and wind resources. Wind Engineering 33: 449-468.

Ashby, S.F. and R.D. Falgout (1996) A parallel multigrid preconditioned conjugate gradient algorithm for groundwater flow simulations. Nucl. Sci. Eng. 124: 145-159.

Beljaars, A.C.M., P. Viterbo, and M.J. Miller (1996) The anomalous rainfall over the United States during July 1993: Sensitivity to land surface parameterization and soil moisture anomalies. Mon. Wea. Rev. 124: 362-383.

Betts, A.K., J.H. Ball, A.C.M. Beljaars, M.J. Miller, and P.A. Viterbo (1996) The land surfaceatmosphere interaction: A review based on observational and global modeling perspectives. J. Geophys. Res. 101(D3): 7209-7225.

Chen, F. and J. Dudhia (2001) Coupling an advanced land surface-hydrology model with the Penn State-NCAR MM5 modeling system. Part I: Model implementation and sensitivity. Mon. Wea. Rev. 129: 569-585.

Chen, F., and R. Avissar (1994) Impact of land-surface moisture variability on local shallow convective cumulus and precipitation in large-scale models. J. Appl. Meteorol. 33: 13821401. 
Chow, F.K., R.L. Street, M. Xue, and J.H. Ferziger (2005) Explicit filtering and reconstruction turbulence modeling for large-eddy simulation of neutral boundary layer flow. J. Atmos. Sci. 62(7, Part 1): 2058-2077.

Chow, F.K. and R.L. Street. Evaluation of turbulence closure models for large-eddy simulation over complex terrain: flow over Askervein Hill. J. Appl. Meteorol. Clim. 48(5): 1050-1065.

Dai, Y., X. Zeng, R.E. Dickinson, I. Baker, G.B. Bonan, M.G. Bosilovich, A.S. Denning, P.A. Dirmeyer, P.R. Houser, G. Niu, K.W. Oleson, C.A. Schlosser, and Z-L. Yang (2003) The Common Land Model. Bull. Amer. Meteorol. Soc. 84(8): 1013-1023.

Delle Monache, L., G. Descombes, B. Kosovic, M. D. Simpson, V. Bulaevskaya, M. Alai, and L. G. Glascoe (2011) Ensemble data assimilation for wind energy applications. In: American Meteorological Society Second Symposium on the New Energy Economy, January 2011, Seattle, WA. Presentation available at http://ams.confex.com/ams/91Annual/webprogram/Paper185473.html

Famiglietti, J.S., D. Ryu, A.A. Berg, M. Rodell, and T.J. Jackson (2008), Field observations of soil moisture variability across scales. Water Resour. Res. 44: W01423.

J Feedman, M Markus, and R Penc (2008) Analysis of West Texas wind plant ramp-up and ramp-down events. AWS Truewind report.

Golaz, J.-C., H. Jiang, and W.R. Cotton (2001) A large-eddy simulation study of cumulus clouds over land and sensitivity to soil moisture. Atmos. Res. 59-60: 373-392.

Grell, G.A., S. Emeis, W.R. Stockwell, T. Schoenemeyer, R. Forkel, J. Michalakes, R. Knoche, and W. Seidl (2000) Application of a multiscale, coupled MM5/chemistry model to the complex terrain of the VOTALP valley campaign. Atmos. Envir. 34(9): 1435-1453.

Gronas S. and AD Sandvik (1999) Numerical simulations of local winds over steep orography in the storm over north Norway on October 12, 1996. J. Geophys. Res. - Atmos. 104(D8): 91079120 .

Hanna, S.R. and R.X. Yang (2001) Evaluations of mesoscale models' simulations of near-surface winds, temperature gradients, and mixing depths. J. Appl. Meteorol. 40(6): 1095-1104.

Holt, T.R., D. Niyogi, F. Chen, K, Manning, M.A. LeMone, and A. Qureshi (2006) Effect of land-atmosphere interactions on the IHOP 24-25 May 2002 convection case. Mon. Wea. Rev. 134: 113-133. 
Jones, J.E., and C.S. Woodward (2001) Newton-Krylov multigrid solvers for large-scale, highly heterogeneous variably saturated flow problems. Adv. Water Resour. 24: 763-774.

Kamath, C. (2010) Using Simple Statistical Analysis of Historical Data to Understand Wind Ramp Events. LLNL Technical Report LLNL-TR-423242, available at https://e-reportsext.1lnl.gov/pdf/386189.pdf.

Kollet, S.J., and R.M. Maxwell (2006) Integrated surface-groundwater flow modeling: A free surface overland flow boundary condition in a parallel groundwater flow model. Adv. Water Resour. 29: 945-958.

Kumar, V., J. Kleissl, C. Meneveau, and M.B. Parlange (2006) Large-eddy simulation of a diurnal cycle of the atmospheric boundary layer: Atmospheric stability and scaling issues. Water Resour. Res.42: W06D09.

Liu, Y., et al. (2011) Simultaneous nested modeling from the synoptic scale to the LES scale for wind energy applications. J. Wind Eng. Ind. Aerodyn.: doi:10.1016/j.jweia.2011.01.013

Lundquist, J.K. (2008) Director's Climate Initiative Wind Energy SMS Task - 2008 Report. LLNL Technical Report LLNL-TR-407754.

Maxwell, R.M., J.K. Lundquist, J. Mirocha, S.G. Smith, C.S. Woodward, and A.F.B. Tompson (2010) Development of a coupled groundwater-atmospheric model. Mon. Wea. Rev. in press.

Mitchell, K.E., D. Lohmann, P.R. Houser, E.F. Wood, J.C. Schaake, A. Robock, B.A. Cosgrove, J. Sheffield, Q. Duan, L. Luo, R.W. Higgins, R.T. Pinker, J.D. Tarpley, D.P. Lettenmaier, C.H. Marshall, J.K. Entin, M. Pan, W. Shi, V. Koren, J. Meng, B.H. Ramsay and A.A. Bailey (2004) The multi-institution North American Land Data Assimilation System (NLDAS): Utilizing multiple GCIP products and partners in a continental distributed hydrological modeling system. J. Geophys. Res.109: D07S90.

Mirocha, J. D., J. K. Lundquist, and B. Kosovic (2011) Implementation of nonlinear subfilter turbulence stress models for large-eddy simulations in the Advanced Research WRF Model. Mon. Wea. Rev.138: 4212-4228.

Mirocha, J.D., F.K. Chow, J.K. Lundquist, and K.A. Lundquist (2007) Improved subfilter turbulence modeling for large eddy simulation using WRF. In: 7th Symposium on the Urban Environment, American Meteorological Society, (13.1):4 pp.

Moeng C.-H., J. Dudhia, J. Klemp, and P. Sullivan (2007) Examining two-way grid nesting for large eddy simulation of the PBL using the WRF model. Mon. Wea. Rev. 135 (6): 2295-2311. 
Olson, J. B. and J. M. Brown (2011) A comparison of model and observed turbulent kinetic energy within coastal barrier jets forced by landfall cyclones. In: American Meteorological Society 24th Conference on Weather and Forecasting/20th Conference on Numerical Weather Prediction, January, 2011, Seattle, WA. Presentation available at http://ams.confex.com/ams/91Annual/webprogram/Paper182597.html

Porter, K. and J. Rogers (2010) Status of centralized wind power forecasting in North America. NREL Technical Report NREL/SR-550-47853, available at http://nrelpubs.nrel.gov/Webtop/ws/nich/www/public/SearchForm

Rubin, Y. (2003) Applied Stochastic Hydrogeology. Oxford University Press, 391 pp.

Schaap, M.G. and F.J. Leij (1998) Database-related accuracy and uncertainty of pedotransfer functions. Soil Sci. 163(10): 765-779.

Seuffert, G., P. Gross, C. Simmer, and E.F. Wood (2002) The influence of hydrologic modeling on the predicted local weather: Two-way coupling of a mesoscale weather prediction model and a land surface hydrologic model. J. Hydrometeor. 3: 505-523.

Skamarock, W. C. and J. B. Klemp (2008) A time-split nonhydrostatic atmospheric model for weather research and forecasting applications. J. Comp. Phys. 227(7): 3465-3485.

Storm B., J. Dudhia, S. Basu, A. Swift, and I. Giammanco (2009) Evaluation of the Weather Research and Forecasting Model on forecasting low-level jets: Implications for wind energy. Wind Energy 12: 81-90.

Tompson, A.F.B., R. Ababou, and L.W. Gelhar (1989) Implementation of the three-dimensional turning bands random field generator. Water Resour. Res. 25(10): 2227-2243.

Wendroth, O., W. Pohl, S. Koszinski, H. Rogasik, C.J. Ritsema, and D.R. Nelson (1999) Spatiotemporal patterns and covariance structures of soil water status in two Northeast-German field sites. J. Hydro. 215: 38-58.

Western, A.W., S.-L. Zhou, R.B. Grayson, T.A. McMahon, G. Blöschl, and D.J. Wilson (2004) Spatial correlation of soil moisture in small catchments and its relationship to dominant spatial hydrological processes. J. Hydro. 286: 113-134.

Wharton, S., and J.K. Lundquist (2010) Atmospheric stability impacts on power curves of tall wind turbines - An analysis of a West Coast North American wind farm. LLNL Technical Report LLNL-TR-424435, available at https://e-reports-ext.1lnl.gov/pdf/387609.pdf 
Williams, J.L., R.M. Maxwell, J.K. Lundquist, and S. Wharton (2009) On the use of a coupled variably-saturated groundwater flow - land surface model to initialize a fully coupled subsurface - land surface - atmospheric model for wind energy forecasting. Eos Trans. AGU Fall Meeting Supplement, 90, abstract A31F-0183.

Williams, J.L., and R.M. Maxwell (2011) Propagating subsurface uncertainty to the atmosphere using fully-coupled, stochastic simulations. J. Hydrometeor., in press.

Woodward, C.S., R.M. Maxwell, J.K. Lundquist, J. Mirocha, S. Smith, and A.F. Tompson (2009) Wind energy resource assessment using coupled groundwater-land-surface atmospheric models. Eos Trans. AGU Fall Meeting Supplement, 90, abstract A31F-0189.

Wyngaard, J.C. (2004) Toward numerical modeling in the "terra incognita". J. Atmos. Sci. 61(14): 1816-1826. 